\title{
CO2 Mass transfer model for carbonic anhydrase-enhanced aqueous MDEA solutions
}

Gladis, Arne Berthold; Deslauriers, Maria Gundersen; Neerup, Randi; Fosbøl, Philip Loldrup; Woodley, John; von Solms, Nicolas

\section{Published in:}

Chemical Engineering Journal

Link to article, DOI:

10.1016/j.cej.2017.10.111

Publication date:

2018

Document Version

Peer reviewed version

Link back to DTU Orbit

Citation (APA):

Gladis, A. B., Deslauriers, M. G., Neerup, R., Fosbøl, P. L., Woodley, J., \& von Solms, N. (2018). CO2 Mass transfer model for carbonic anhydrase-enhanced aqueous MDEA solutions. Chemical Engineering Journal, 335 , 197-208. https://doi.org/10.1016/j.cej.2017.10.111

\section{General rights}

Copyright and moral rights for the publications made accessible in the public portal are retained by the authors and/or other copyright owners and it is a condition of accessing publications that users recognise and abide by the legal requirements associated with these rights.

- Users may download and print one copy of any publication from the public portal for the purpose of private study or research.

- You may not further distribute the material or use it for any profit-making activity or commercial gain

- You may freely distribute the URL identifying the publication in the public portal 


\section{Accepted Manuscript}

$\mathrm{CO}_{2}$ Mass transfer model for carbonic anhydrase-enhanced aqueous MDEA solutions

Arne Gladis, Maria T Gundersen, Randi Neerup, Philip L Fosbøl, John M Woodley, Nicolas von Solms

PII: $\quad$ S1385-8947(17)31826-0

DOI: $\quad$ https://doi.org/10.1016/j.cej.2017.10.111

Reference: $\quad$ CEJ 17895

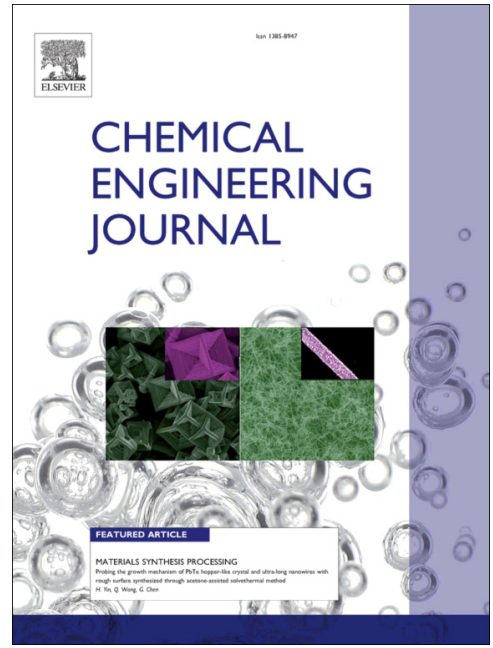

To appear in: $\quad$ Chemical Engineering Journal

Received Date: $\quad 27$ March 2017

Revised Date: $\quad 14$ October 2017

Accepted Date: $\quad 18$ October 2017

Please cite this article as: A. Gladis, M.T. Gundersen, R. Neerup, P.L. Fosbøl, J.M. Woodley, N. von Solms, $\mathrm{CO}_{2}$ Mass transfer model for carbonic anhydrase-enhanced aqueous MDEA solutions, Chemical Engineering Journal (2017), doi: https://doi.org/10.1016/j.cej.2017.10.111

This is a PDF file of an unedited manuscript that has been accepted for publication. As a service to our customers we are providing this early version of the manuscript. The manuscript will undergo copyediting, typesetting, and review of the resulting proof before it is published in its final form. Please note that during the production process errors may be discovered which could affect the content, and all legal disclaimers that apply to the journal pertain. 
$\mathrm{CO}_{2}$ Mass transfer model for carbonic anhydrase-enhanced aqueous MDEA solutions

Arne Gladis $^{{ }^{*}}$, Maria T Gundersen ${ }^{2}$, Randi Neerup ${ }^{l}$, Philip L Fosbøl, John M Woodley ${ }^{2}$, Nicolas von Solms ${ }^{1}$

1) Center for Energy Resources Engineering, Department of Chemical and Biochemical Engineering, Technical University Denmark, Kgs. Lyngby 2800 PROSYS Center, Department of Chemical and Biochemical Engineering, Technical University Denmark, Kgs. Lyngby 2800

*Corresponding Authors email: arng@ @kt.dtu.dk

Highlights:

- $\mathrm{CO}_{2}$ mass transfer models developed for CA enhanced MDEA solutions.

- Mass transfer model on basis of mechanistic enzyme model.

- Influence of temperature, solvent concentration, $\mathrm{CO}_{2}$ partial pressure and solvent loading on enzyme kinetics described.

- Model validation for $298-328 \mathrm{~K}, 15-50 \mathrm{wt} \% \mathrm{MDEA}$, up to $50 \mathrm{kPa} \mathrm{CO}_{2}$ for absorption and desorption.

\section{Keywords:}

Wetted wall column, carbonic anhydrase, carbon capture, enzyme kinetics, MDEA, carbon dioxide 


\begin{abstract}
:
In this study a $\mathrm{CO}_{2}$ mass transfer model was developed for carbonic anhydrase-enhanced MDEA solutions based on a mechanistic kinetic enzyme model. Four different enzyme models were compared in their ability to predict the liquid side mass transfer coefficient at temperatures in the range of 298 to $328 \mathrm{~K}$, solvent concentrations in the range 15 to $50 \mathrm{wt} \%, \mathrm{CO}_{2}$ partial pressures up to $50 \mathrm{kPa}$, solvent loading between 0 and 0.5 mole $\mathrm{CO}_{2}$ per mole MDEA and enzyme concentrations up to $8.5 \mathrm{~g} / \mathrm{L}$. The reversible Michaelis Menten model (MR) and the simplified model with product inhibition by the bicarbonate ion (SP) were able to predict the mass transfer with an absolute average relative deviation of less than $15 \%$. The MR model could account for every influence (solvent concentration, temperature, solvent loading, $\mathrm{CO}_{2}$ partial pressure) of the different process conditions on the mass transfer, whereas the SP model is limited to applications with low $\mathrm{CO}_{2}$ partial pressure such as CCS from coal burning power plants. Two other models that were also investigated are not suitable for implementation into an absorber column simulation, as they cannot describe the influence of changing solvent loading on the mass transfer.
\end{abstract}




\section{Introduction:}

Reactive absorption technology can be applied for carbon capture in post combustion at large point sources such as fossil fuel-burning power plants. In the near future it can help to achieve the ambitious goals in greenhouse gas reduction while also ensuring a safe and stable energy supply. This technology is already applied in several industrial processes where mixed gas streams are cleansed of $\mathrm{CO}_{2}$, such as in natural gas treatment, biogas purification, synthesis gas production and ammonia production. However, there are still challenges for application in post combustion, because of the large gas volumes to be treated, and the low concentration of $\mathrm{CO}_{2}$ in the exhaust gases.

For processes with very low $\mathrm{CO}_{2}$ driving forces reactive (also called chemical) absorption technology is suitable as the mass transfer rates are enhanced by a chemical reaction. The reaction is crucial. It depletes the $\mathrm{CO}_{2}$ near the interface which results in higher diffusion and therefore enhances the mass transfer. The absorption in CCS applications are carried out in kinetically controlled regimes, thus the reaction rates are primarily influencing the mass transfer rates.

In a general process outline a chemical solvent is introduced into the absorber column at the top. It is called the lean solvent, since the $\mathrm{CO}_{2}$ content, comprising of physical bound $\mathrm{CO}_{2}$ and various reaction products is low. The flue gas coming from the power plant exhaust is blown by a fan from the bottom of the absorber through the column with a counter-currently descending liquid flow in contact. $\mathrm{CO}_{2}$ from the gas is dissolved in the liquid and reacts with the solvent forming carbamates, and/or bicarbonates. The "rich" solvent, with high amount of chemically bound $\mathrm{CO}_{2}$ leaves the absorber bottom. It is pumped into the desorber, where the chemical and 
thermodynamic equilibrium are shifted by an increase in temperature and $\mathrm{CO}_{2}$ is released from the solvent.

In order to optimize the process, capital and operating costs should be minimized. For lower capital costs the equipment size should be reduced. The size of the absorber, which has the highest contribution to the overall capital costs in a conventional system, can be reduced if the mass transfer can be increased. This can be achieved by higher reaction rates of the solvent with $\mathrm{CO}_{2}$. For optimizing the operating costs, the heat requirement in the desorber should be targeted, as it makes up to $90 \%$ of the total operating costs, excluding the compression stage [1]. It remains a big challenge to optimize capital costs and operating costs together, as there is a relation between reaction speed and heat of reaction [1]. This implies that fast reacting solvents which result in smaller mass transfer equipment and lower capital costs need more energy in the reboiler to reverse the reactions. On the other hand, solvents with low heat of reaction are very slow absorbing and thus lead to uneconomical equipment sizes.

The use of catalysts can speed up the reactions rates of slow solvents while maintaining the low heat of reaction. One catalyst which increases the reversible reaction rate between $\mathrm{CO}_{2}$ and water is the enzyme carbonic anhydrase (E.C.4.2.1.1.) (CA) [2]. The aim of this study is to derive a mechanistic kinetic model for the catalyzed reactions by CA in the tertiary amine MDEA from $\mathrm{CO}_{2}$ mass transfer experiments. The model should be capable, once implemented in a column model to predict the mass transfer accurately across a wide range of process conditions, such as varying temperature, solvent concentration, solvent loading and enzyme concentration for both absorption and desorption. 


\section{Enzymes}

Enzymes are biological catalysts that reduce the activation energy of (bio)chemical reactions. The main advantages for enzyme based catalysis compared to conventional catalysts are the high regio- and stereo-selectivity, the possibility to perform the reaction in mild conditions, which therefore needs less energy (e.g. lower process temperature), and low by-product generation.

However, enzymes are also unstable at certain process conditions. Their stability is dependent on $\mathrm{pH}$, temperature and salt or organic compound concentration.

\subsection{CA Mechanism}

The $\mathrm{CA}$ enzyme was discovered when the high mass transfer rates of $\mathrm{CO}_{2}$ in blood were investigated by Meldrum and Roughton [4]. The interconversion of $\mathrm{CO}_{2}$ and bicarbonate catalyzed by carbonic anhydrase could explain why $\mathrm{CO}_{2}$ mass transfer rates higher than physical absorption could be obtained. The overall reaction of CA enzyme observed was:

$\mathrm{CO}_{2}+\mathrm{H}_{2} \mathrm{O} \stackrel{\mathrm{CA}}{\leftrightarrow} \mathrm{HCO}_{3}^{-}+\mathrm{H}^{+}$

The active site of carbonic anhydrase is a $\mathrm{Zn}^{2+}$ ion with an attached hydroxyl group. The reaction mechanism of $\alpha$-CAs is well studied; a scheme is shown in Figure 1. The figure is adapted from Pierre [5] to show the mechanism from a different angle,as it includes the proton channel into the overall reaction mechanism. Even though the $\beta$ - and $\gamma$-family have different protein sequence, the main mechanism of $\mathrm{CO}_{2}$ hydration shows similarities concerning the rate limiting steps [7][6]. All CA types involve a $\mathrm{CO}_{2}$ hydration of a zinc bound hydroxide ion as well as a proton removal from water bound to zinc and proton transfer to a side amino acid chain [8]. 
The pictogram in Figure 1 show a CA enzyme is in its active state with a hydroxide ion bound to zinc and a $\mathrm{CO}_{2}$ molecule nearby (A), the amino acid side chain, here referred to as proton channel (PC) is releasing a proton to a buffer molecule in the solution, in the intermolecular proton transfer. The zinc bound hydroxyl then reacts with the nearby carbon dioxide molecule via a nucleophilic attack onto the $\mathrm{C}$-atom (B) resulting in a zinc-bound bicarbonate. The bicarbonate is swapped by a water molecule releasing bicarbonate to solution $(\mathrm{C})$, leaving the enzyme in an inactive state with water bound to the zinc (D). To regain its catalytic activity one proton has to be removed from the zinc-bound water molecule. The proton is transferred via PC; this step is called the intramolecular proton transfer. This transfer occurs over intervening hydrogen bonded water molecules as the two functional groups are not close to each other. The transfer involves between 2 and 3 water molecules for $\alpha$-CA [7], [9], although this value might vary for different enzymes.

As the buffer concentration must be lower than $10 \mathrm{mM}$ [10] to make the intermolecular proton transfer rate limiting, in carbon capture applications with solvent concentration in the order of 1 $\mathrm{M}$ the rate limiting step is considered to be the transfer of the proton to the side chain PC. The overall reaction can then be described as:

$\mathrm{CO}_{2}+\mathrm{H}_{2} \mathrm{O}+\mathrm{B} \leftrightarrow \mathrm{CA}_{\leftrightarrow} \mathrm{CO}_{3}^{-}+\mathrm{BH}^{+}$

B represents any kind of proton acceptor such as hydroxyl ions or a base. The enzyme catalyzes the reversible reactions towards the chemical equilibrium. If the concentration of bicarbonate is lower than the chemical equilibrium, $\mathrm{CO}_{2}$ is consumed. If it is higher, $\mathrm{CO}_{2}$ will be produced from bicarbonate and the reaction follows a counterclockwise path in Figure 1. 


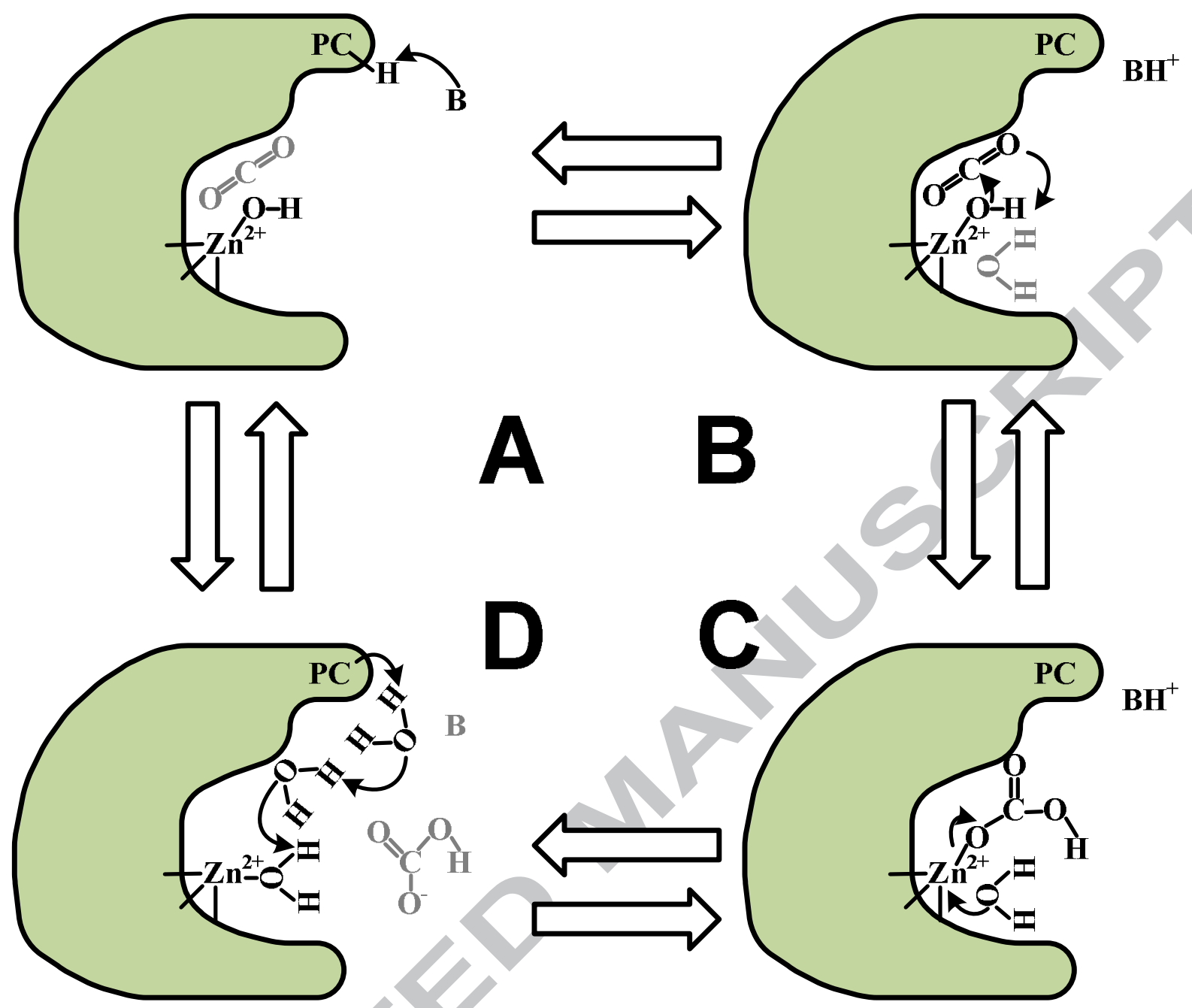

Figure 1: Reaction mechanism of $\alpha$-carbonic anhydrase, adapted from Pierre [5]

In order to evaluate the potential of $\mathrm{CA}$ as a kinetic promoter in carbon capture, detailed process simulations are required. These process simulations need to solve the mass transfer with incorporated enzyme kinetics and need to be valid across a wide range of process conditions.

\subsection{Reversible Michaelis Menten Kinetics}

The Michaelis Menten enzyme kinetics mark the transition between homogeneous and heterogeneous catalysis [3]. Assuming a reversible enzyme reaction between substrate $\mathrm{S}$ and product P over an enzyme substrate complex E-S 
$S+E \underset{k_{-1}}{\stackrel{k_{1}}{\rightleftarrows}} E-S \underset{k_{-2}}{\stackrel{k_{2}}{\rightleftarrows}} E+P$

This will give a reaction rate, expressed as production of product $\mathrm{P}$ :

$\frac{d C_{P}}{d t}=k_{2} \cdot C_{E-S}-k_{-2} \cdot C_{P} \cdot C_{E}=r$

And a rate equation for the enzyme-substrate complex of:

$\frac{d C_{E-S}}{d t}=k_{1} \cdot C_{S} \cdot C_{E}+k_{-2} \cdot C_{P} \cdot C_{E}-\left(k_{-1}+k_{2}\right) \cdot C_{E-S}$

Together with the mass balance for the enzyme:

$C_{E}=C_{E T o t}-C_{E-S}$

The concentration of enzyme substrate complex is assumed constant $\left(\frac{d C_{E-S}}{d t}=0\right)$, which holds true if the substrate concentration is much higher than the enzyme concentration. Then relations between total enzyme concentration $C_{E T o t}$, free enzyme concentration $C_{E}$ and enzyme-substrate concentration $C_{E-S}$ can be derived. Inserting these concentrations into Eq. (3) together with the following transformations:

$r_{\max 1}=k_{2} \cdot C_{E T o t}$

$$
\begin{aligned}
& r_{\text {max } 2}=k_{-1} \cdot C_{E T o t} \\
& K_{M S}=\frac{k_{-1}+k_{2}}{k_{1}} \\
& K_{M P}=\frac{k_{-1}+k_{2}}{k_{-2}}
\end{aligned}
$$


Where $K_{M S}$ and $\left.K_{M P}(\mathrm{~mol} \mathrm{~m})^{-3}\right)$ are the Michaelis Menten constants for the forward and reverse reactions respectively and $r_{\max 1}$ and $r_{\max 2}$ are the maximal forward and reverse reaction rates. This leads to:

$r=\frac{r_{\max 1} \cdot C_{S} \cdot K_{M P}-r_{\max 2} \cdot C_{P} \cdot K_{M S}}{K_{M P} \cdot C_{S} \cdot+K_{M S} \cdot C_{P}+K_{M P} \cdot K_{M S}} \cdot C_{E T o t}$

Using the Haldane relationship for the connection between thermodynamic and kinetic equilibrium [11]:

$K_{e q}=\frac{C_{P}^{e q}}{C_{S}^{e q}}=\frac{r_{\max 1} \cdot K_{M P}}{r_{\max 2} \cdot K_{M S}}$

Under the assumption that the liquid bulk is in chemical equilibrium, thus $C_{P}$ is linked to $C_{S}^{e q}$ through the thermodynamic equilibrium constant $K_{e q}$ the reaction rate can be described as:

$r=\frac{r_{\max 1}\left(C_{S}-C_{S}^{e q}\right)}{K_{M S} \cdot\left(1+\frac{C_{P}}{K_{M P}}\right)+C_{S}}$

Eq. (10) is the expression of an enzyme reaction rate for a reversible reaction following Michaelis Menten kinetics. The term product inhibition is often used when the reaction rate is lowered with an increasing product concentration. It is though often misleading since it is not an inhibition but the Michaelis-Menten kinetics for the reverse reaction causing this decrease. Just in case the reaction is irreversible that effect can be explained by a product inhibition.

\subsection{Kinetic enzyme model development}

Kinetic models should be as simple as possible and as accurate as necessary. Here several kinetic models for the enzyme kinetics will be derived, with different level of complexity and each model will be tested on how good it can describe the different changing process parameters. 


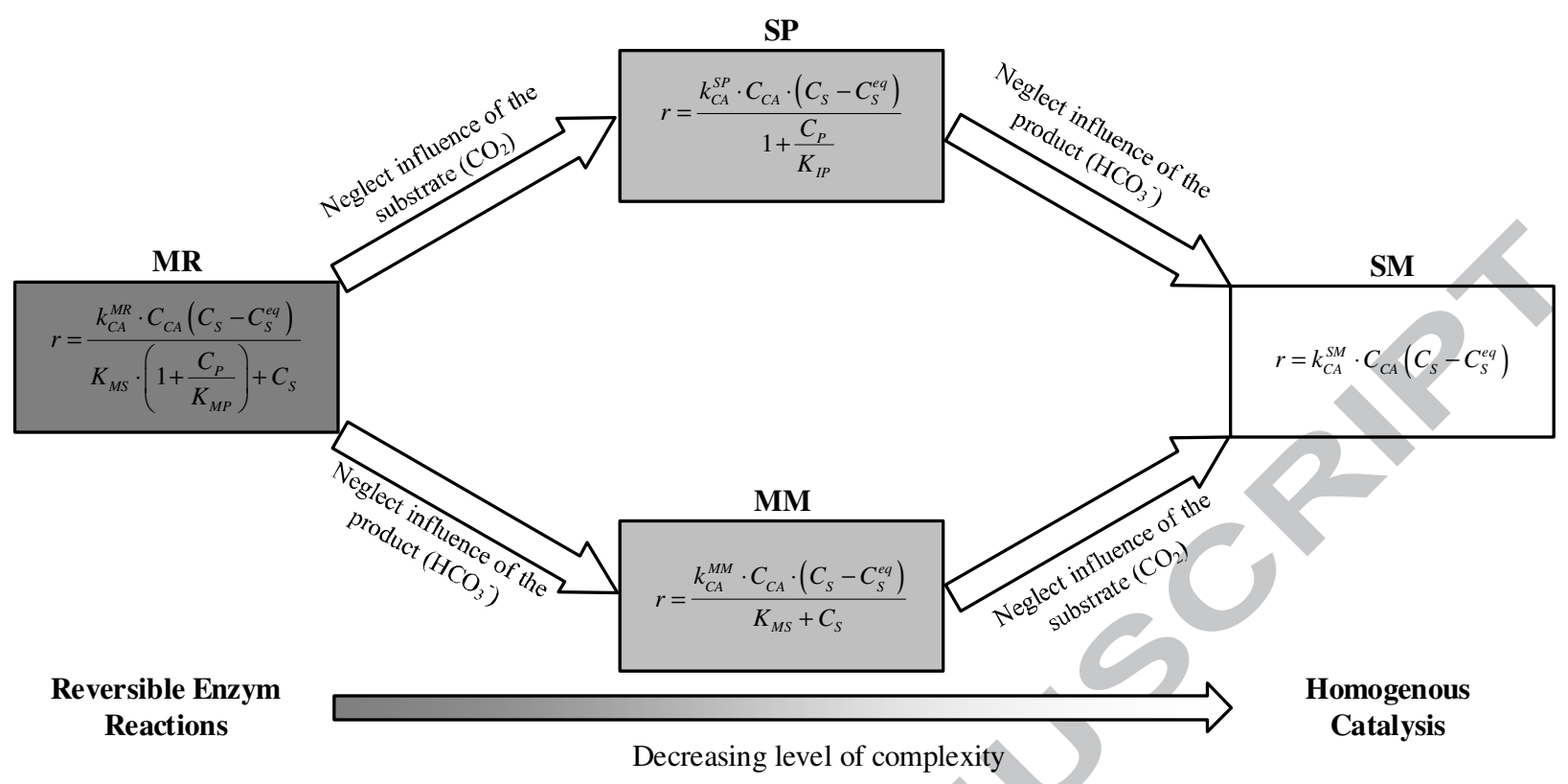

Figure 2: Relation of the different kinetic enzyme models

The most complex model is the reversible Michaelis Menten (MR) model:

$$
r=\frac{k_{C A}^{M R} \cdot C_{C A}\left(C_{S}-C_{S}^{e q}\right)}{K_{M S} \cdot\left(1+\frac{C_{P}}{K_{M P}}\right)+C_{S}}
$$

This model can be simplified, assuming, that the product concentration is not affecting the rate.

The following expression of the model is similar to the general Michaelis Menten equation for a forward reaction and is therefore denoted with MM:

$r=\frac{k_{C A}^{M M} \cdot C_{C A}\left(C_{S}-C_{S}^{e q}\right)}{K_{M S}+C_{S}}$

The simplest model is the simplified Michaelis-Menten model (SM) model which assumes, that also the substrate concentration has no influence on the rate:

$r=\frac{k_{C A} \cdot C_{C A}\left(C_{S}-C_{S}^{e q}\right)}{K_{M S}+C_{S}} \approx k_{C A}^{S M} \cdot C_{C A}\left(C_{S}-C_{S}^{e q}\right)$

In that model the enzyme reaction kinetics are modelled analogous to an homogenous catalysis. 
Starting with the MR model, under the assumption that the substrate has no influence on the reaction rate, but the product has, a fourth model called SP can be established.

$r=\frac{k_{C A}^{S P} \cdot C_{C A}\left(C_{S}-C_{S}^{e q}\right)}{1+\frac{C_{P}}{K_{I P}}}$

An overview of the different models and the number of relevant parameters is given in Table 1 and a link between the different models is given in Figure 2.

Table 1: Overview of the different kinetic enzyme models

\begin{tabular}{|c|c|c|c|l|}
\hline & Description & $\begin{array}{l}\text { Mathematical } \\
\text { context }\end{array}$ & $\begin{array}{l}\text { Number of fitted } \\
\text { parameters }\end{array}$ & Parameters \\
\hline MR & $\begin{array}{c}\text { Reversible enzyme kinetics } \\
\text { (Michaelis Menten) }\end{array}$ & Eq. (11) & 3 & $k_{C A}^{M R}, K_{M S}, K_{M P}$ \\
\hline $\mathbf{M M}$ & $\begin{array}{c}\text { Michaelis Menten type } \\
\text { forward reaction }\end{array}$ & Eq. (12) & 2 & $k_{C A}^{M M}, K_{M S}$ \\
\hline $\mathbf{S P}$ & $\begin{array}{c}\text { Simple enzyme model with } \\
\text { product inhibition }\end{array}$ & Eq. (14) & 2 & $k_{C A}^{S P}, K_{I P}$ \\
\hline $\mathbf{S M}$ & \begin{tabular}{c} 
Simple enzyme model \\
\hline
\end{tabular} & Eq. (13) & 1 & $k_{C A}^{S M}$ \\
\hline
\end{tabular}

2.4. Kinetic enzyme models for $\mathrm{CA}$ in scientific literature

The kinetics of CA has been of interest for a long time due to its physiological importance for the living organisms. The recently addressed application for carbon capture purposes has increased the interest even further. The focus of these two approaches is though different, the former aims to describe the interconversion of physically bound $\mathrm{CO}_{2}$ and bicarbonate in highly diluted aqueous buffer solutions at close to neutral $\mathrm{pH}$. In contrast, the latter approach aims to describe the mass transfer of $\mathrm{CO}_{2}$ into concentrated buffer solutions with high $\mathrm{pH}$ in unit operations such as absorber and desorber towers on the basis of a mass transfer model with incorporated enzyme kinetics. The complexity and level of detail for the physiological model on the one hand may be 
troublesome to implement into an already very complex absorber model, on the other hand some effects of these models, like for example the influence of water concentration might be overlooked, because the water concentration does not change significantly when small amounts of salt or buffer are added, whereas in carbon capture solvents the molar water concentration might be half of the value of pure water. Also the $\mathrm{CO}_{2}$ concentration in the liquid phase might be quite different in these two approaches.

Russo et al. [12] implemented a kinetic model for CA into a bubble column to simulate the mass transfer. For the case of free flowing enzyme they used a reaction rate equation in the following form:

$$
r=\frac{k_{c a t} \cdot C_{C A}\left(C_{S}-\frac{C_{S}^{e q} \cdot C_{H+} \cdot C_{H_{2} O}}{C_{H+}^{e q} \cdot C_{H_{2} O}^{e q}}\right)}{K_{M S}+C_{S}-\frac{C_{S}^{e q} \cdot C_{H+} \cdot C_{H_{2} O}}{C_{H+}^{e q} \cdot C_{H_{2} O}^{e q}}}
$$

The expression of the rate equation was slightly changed to match our notation. They described the basis for this model to be a reversible Michaelis Menten enzyme kinetics, where the product inhibition and the buffer protonation could be neglected. Assuming equilibrium for the product $\left(C_{H_{+}}=C_{H+}^{e q}\right.$ and $\left.C_{H_{2} \mathrm{O}}=C_{\mathrm{H}_{2} \mathrm{O}}^{e q}\right)$, so the water and proton concentrations are cancelling out, will lead to an expression similar to the Michaelis Menten model (MM) described in Eq. (12). The only difference between these two models is that in the Russo et al. model has a denominator term which subtract the substrate concentration in equilibrium with the product concentration $C_{S}^{e q}$. Russo et al. [12] took this expression from the work of Praveen et al. [13] where it is regarded as reversible Michaelis Menten kinetic. In the work of Segel [14], the kinetic expression derived for a reversible reaction is the same form as derived in this work and described in in Eq. (11). The expression from Eq. (15) describes the progress curve phase of an 
enzyme reaction according to Michalis Menten kinetics, but is just considering the forward reaction and no back reaction, according to Cornish-Bowden [15].

Larachi et al. [16] simulated a packed bed scrubber and a Robinson Mahoney reactor with immobilized CA. The reversible enzyme reactions were modelled with the following reaction rate equation:

$r=\frac{k_{c a t} \cdot C_{C A} \cdot C_{S}}{K_{M S} \cdot\left(1+\frac{C_{P}}{K_{M P}}\right)+C_{S}}-\frac{k_{-c a t} \cdot C_{C A} \cdot C_{P}}{K_{M P} \cdot\left(1+\frac{C_{S}}{K_{M S}}\right)+C_{P}}$

Applying the Haldane relationship from Eq. (9) will result in the exact same expression as the reversible Michaelis Menten model (MR) in Eq. (11).

Penders van Elk et al. derived a kinetic model for CA in MDEA [10]. Based on their observation the reaction rate declined when the MDEA concentration was higher. They ascribed this trend to the lower water concentration and derived an enzyme kinetic reaction that is dependent on the water concentration.

$r=\frac{k_{3}^{*} \cdot C_{C A}}{1+k_{4}^{*} \cdot C_{C A}} \cdot C_{C_{H_{2} \mathrm{O}}} \cdot C_{S}$

The framework of this model is similar SM (Eq. (13)). The difference is in the enzyme contribution to the enzyme reaction which has a non-linear relation. Penders van Elk et al. used a Langmuir Hinshelwood expression instead. There is no mechanistic explanation for using this approach other than it fits the course of the curve and describes the deviation from linear correlation between enzyme reaction rate and enzyme concentration observed at higher enzyme concentrations. The model presented here is of special interest since it is the only model derived for MDEA solutions whereas the other models were developed for carbonate salt solutions. 
Zhang et al. [18] also used the SM approach for their kinetic model of $20 \mathrm{wt} \% \mathrm{~K}_{2} \mathrm{CO}_{3}$. In their experiments they did not observe an influence of temperature nor bicarbonate concentration on the reaction rate for temperatures between $298 \mathrm{~K}$ and $323 \mathrm{~K}$ and solvent loading between 0.1 and 0.4 mole $\mathrm{CO}_{2}$ per mole $\mathrm{K}_{2} \mathrm{CO}_{3}$.

$\mathrm{Hu}$ et al. [19] derived a kinetic model in the temperature range 298 to $328 \mathrm{~K}$ using a stopped flow cell for water. They observed a decrease in first order reaction rate using a wetted wall column with 30 wt $\% \mathrm{~K}_{2} \mathrm{CO}_{3}$ at $323 \mathrm{~K}$ at higher $\mathrm{CO}_{2}$ loading, but did not attempt to implement the decrease in absorption with higher loading in their model.

A list of the different kinetic models and process conditions considered is given Table 2. None of the existing models in literature incorporated the influence of more than 2 process conditions.

Table 2: Kinetic model of CA in CCS applications: Overview of the considered influencing process conditions

\begin{tabular}{lccccc}
\hline Reference & Solvent & Solvent conc. & Temperature & $\mathbf{p C O}_{2}$ & loading \\
\hline $\begin{array}{l}\text { Russo et al.[20] } \\
\text { Larachi et al. [16] }\end{array}$ & $\mathrm{K}_{2} \mathrm{CO}_{3}$ & - & - & $\checkmark$ & - \\
$\begin{array}{l}\text { Penders-van Elk et } \text { al. [10], } \\
\text { [21] }\end{array}$ & $\mathrm{MDEA}$ & - & - & $\checkmark$ & $\checkmark$ \\
Zhang et al. [18] & $\mathrm{K}_{2} \mathrm{CO}_{3}$ & - & $\checkmark$ & - & - \\
Hu et al. [19] & water & - & $\checkmark$ & - & $\checkmark$ \\
This work & MDEA & $\checkmark$ & $\checkmark$ & $\checkmark$ & - \\
\hline
\end{tabular}




\section{Theory on mass transfer and kinetics}

\subsection{Chemical reactions of $\mathrm{CO}_{2}$ and MDEA}

The typical amine solvent is mixed with water. The presence of water results in a more complex reaction mechanism. The water creates a possibility for ionic species which in addition to water can react with $\mathrm{CO}_{2}$ :

$\mathrm{CO}_{2}+\mathrm{H}_{2} \mathrm{O} \leftrightarrow \mathrm{H}_{2} \mathrm{CO}_{3}$

$\mathrm{CO}_{2}+\mathrm{OH}^{-} \leftrightarrow \mathrm{HCO}_{3}^{-}$

The contribution of reaction Eq. (18) to the overall reaction can be neglected for aqueous amine solutions because it is very slow in comparison to the other reactions [22]. The kinetics of reaction (19) can be described with a second order reversible reaction rate:

$r_{\mathrm{CO}_{2}}=k_{\mathrm{OH}^{-}} \cdot \mathrm{C}_{\mathrm{OH}^{-}} \cdot\left(C_{\mathrm{CO}_{2}}-C_{\mathrm{CO}_{2}}^{e q}\right)$

The concentration of $\mathrm{OH}^{-}$ions in amine solutions can be estimated using a thermodynamic activity model, such as extended UNIQUAC or Elec-NRTL, or literature correlations.

Tertiary amines with their three substituents on the nitrogen group cannot react directly with a $\mathrm{CO}_{2}$ molecule, in contrast to primary and secondary amines. A base catalysis mechanism describes the reaction of MDEA, leading to the following reaction mechanism [23]:

$\mathrm{CO}_{2}+M D E A+\mathrm{H}_{2} \mathrm{O} \leftrightarrow \mathrm{HCO}_{3}^{-}+M D E A H^{+}$

The overall reaction rate for a reversible reaction can be described with a second order rate constant $k_{2 M D E A}\left(\mathrm{~m}^{3} \mathrm{~mol}^{-1} \mathrm{~s}^{-1}\right)$, as well as the amine and $\mathrm{CO}_{2}$ concentration

$$
r_{C O_{2}}=k_{2 M D E A} \cdot C_{M D E A} \cdot\left(C_{C O_{2}}-C_{C O_{2}}^{e q}\right)
$$

This indirect reaction mechanism is the reason why the reaction kinetics of tertiary amines is much slower than that of primary/secondary amines [24]. 


\subsection{Mass transfer theory with reversible reactions}

The mass transfer between two phases can be described by a quotient of driving force, i.e. the difference in chemical equilibria usually expressed in more accessible units like partial pressures or concentration differences, and an overall mass transfer resistance being the sum of all mass transfer resistances in the different phases. For chemical absorption the mass transfer of $\mathrm{CO}_{2}$ can be described with the following formula:

$N_{\mathrm{CO}_{2}}=\frac{\left(P_{\mathrm{CO}_{2}}^{g a s}-\mathrm{H}_{\mathrm{CO}_{2}} \cdot C_{\mathrm{CO}_{2}}^{l i q}\right)}{\frac{1}{k_{\mathrm{CO}_{2}}^{g a s}}+\frac{\mathrm{H}_{\mathrm{CO}_{2}}}{k_{C O_{2}}^{l i q 0} \cdot E}}$

With $\mathrm{N}_{\mathrm{CO}_{2}}$ being the flux of $\mathrm{CO}_{2}$ transferred per unit area $\left(\right.$ mole $\mathrm{m}^{-2} \mathrm{~s}^{-1}$ ), $P_{\mathrm{CO}_{2}}^{g a s}$ (Pa) being the partial pressure of $\mathrm{CO}_{2}$ in the gas bulk phase. $\mathrm{H}_{\mathrm{CO}_{2}}\left(\mathrm{~Pa} \mathrm{~m}^{3} \mathrm{~mol}^{-1}\right)$ is the apparent Henry coefficient which correlates the composition of the gas and liquid phase which are in equilibrium; $C_{\mathrm{CO}_{2}}^{l i q}\left(\right.$ mole m$\left.{ }^{-3}\right)$ is the concentration of $\mathrm{CO}_{2}$ in the liquid bulk, the product of $C_{\mathrm{CO}_{2}}^{l i q}$ and $\mathrm{H}_{\mathrm{CO}_{2}}$ is the equilibrium partial pressure of the liquid phase $P_{\mathrm{CO}_{2}}^{e q} \cdot k_{\mathrm{CO}_{2}}^{g a s}\left(\right.$ mole $\left.\mathrm{Pa}^{-1} \mathrm{~m}^{-2} \mathrm{~s}^{-1}\right)$ and $k_{\mathrm{CO}_{2}}^{l i q 0}\left(\mathrm{~m} \mathrm{~s}^{-1}\right)$ are the physical mass transfer coefficients for the gas and liquid phase respectively, thus their reciprocal values equals the mass transfer resistance in each phase. E (-) is the enhancement factor which accounts for the effect of chemical reactions on the mass transfer. It describes the intensification of mass transfer due to chemical reactions and it can be explained as ratio of mass transfer with chemical reaction to the hypothetical mass transfer in absence of chemical reaction at the same driving force. The expression from Eq. (23) is valid for physical absorption at $\mathrm{E}=1$.

The enhancement factor $\mathrm{E}$ for a mass transfer operation of compound $\mathrm{A}\left(\mathrm{CO}_{2}\right)$ from the gas phase into the liquid phase with a consequent reaction with compound B (solvent) from the liquid phase is a function of physical mass transfer as well as reaction kinetics of the reaction between $\mathrm{A}$ and 
B. Generally valid analytical solutions cannot be obtained for mass transfer accompanied by a reversible chemical reaction [25]. Approximation/linearization techniques are thus used to estimate the enhancement factors which apply the dimensionless Hatta number Ha.

The Hatta number Ha correlates the maximal conversion due to reaction in the liquid film to the maximal transport through diffusion in absence of chemical reaction. For the MDEA reaction as in Eq. (22), the Hatta number is:

$H a=\frac{\sqrt{k_{2 M D E A} \cdot C_{M D E A}^{b u l k} \cdot D_{C O_{2}}^{l i q}}}{k_{C O_{2}}^{l i q 0}}$

Gaspar and Fosbøl [26] derived a general model for the enhancement factor, called GM model, which is set up for reversible $(m+n)$ order reactions. They set up several bridging relations between the interfacial and the bulk concentration for the reactants, A and B as well as the products $\mathrm{C}$ and $\mathrm{D}$ and deduced the system to a single algebraic equation:

$E=H a \sqrt{y_{B}^{i n t}} \frac{1-y_{A}^{*}}{1-y_{A}^{b}}$

With $y_{A}^{b}, y_{A}^{*}$ and $y_{B}^{i}$ being dimensionless compositions defined as:

$y_{A}^{*}=\frac{y_{A}^{b} \cdot y_{C}^{i n t} \cdot y_{D}^{i n t}}{y_{B}^{i n t}} ; y_{A}^{b}=\frac{C_{A}^{b}}{C_{A}^{i n t}} ; y_{B}^{i n t}=\frac{C_{B}^{i n t}}{C_{B}^{b}}$

The ratio of interfacial and bulk solvent concentration $y_{B}^{i}$ can be calculated from:

$\left(1-E_{f i l m}^{\infty}\right) y_{B}^{i n t}+H a\left(y_{A}^{*}-1\right) \sqrt{y_{B}^{i n t}}+E_{f i l m}^{\infty}-y_{A}^{b}=0$

The Enhancement factor E can be calculated by iteratively solving Eq. (25) and (27). 
The maximum achievable Enhancement factor $E_{\text {film }}^{\infty}$ for a second order reaction according to the film theory is:

$E_{\text {film }}^{\infty}=1+\frac{D_{B} \cdot C_{B}}{\vartheta_{A B} D_{A} \cdot C_{A}^{i n t}}$

With $\vartheta_{A B}$ being the reaction stoichiometry between solvent B and volatile absorbed compound A.

The case explained above (Eq. (25)) assumed that only one reaction with $\mathrm{CO}_{2}$ occurs in the liquid film. An overall reaction in aqueous media of an amine solvent consists of several parallel reactions, this reactions have to be accounted for in the Enhancement factor calculation.

The overall Enhancement factor of a second order reaction can just be described as function of the single reactions Enhancement factors, if the reactions are considered irreversible.

There are three asymptotic behaviors for parallel non-interacting second order reactions; the first treats the case of very low kinetics and is therefore of no interest for this study. The second case treats the case of first order approach where both reactions are behaving in pseudo first order. The enhancement factor for the overall mass transfer can be calculated under these conditions [25]:

$E_{o v}^{p s .1}=\sqrt{\sum_{i} E_{i}^{2}}$

In the third case the reactions are instantaneous, the overall Enhancement factor can be calculated according to [29]:

$E_{o v}^{i n s t}=\sum_{i}\left(E_{i}^{\infty}-1\right)+1$

For the latter cases the expression from Eq. (29) will be used, as it is assumed that the pseudo first order approach is closer to the experimental case than the instantaneous reaction. 


\subsection{Combination of solvent and enzyme kinetics}

The enzyme kinetics are determined by fitting a mass transfer model incorporating a kinetic model against experimental data derived from mass transfer experiments in a wetted wall column.

The mass transfer flux equation in Eq. (23) is used together with correlations for $k_{\mathrm{CO}_{2}}^{l i q 0}$ and $k_{\mathrm{CO}_{2}}^{g a s}$, discussed in a previous study [30]. The Enhancement factor is calculated from a solvent Enhancement factor and an enzyme Enhancement factor using the combination rule from Eq. (29). Both single Enhancement factors are calculated with the GM model for second order reversible reactions [26]. The solvent reaction rate of MDEA is calculated according to Eq. (22) the enzyme reaction rate is calculated from the following correlation:

$r_{\mathrm{CO}_{2}}=r_{\mathrm{CO}_{2}}^{e n z} \cdot C_{\mathrm{H}_{2} \mathrm{O}}^{v_{\mathrm{H}_{2} \mathrm{O}}} \cdot C_{\mathrm{MDEA}}^{v_{\mathrm{MDEA}}}$

Here $r_{\mathrm{CO}_{2}}^{e n z}$ is one of the arbitrary enzyme models described in section 2.3 . The unit of $k_{C A}$ is dependent on the model used and the number of reactants. The reactants in this case might be MDEA and water and the powers $v_{H_{2} O}$ and $v_{M D E A}(-)$ according to the power law. The power of each reactant will be determined from experiments at different solvent concentrations.

\subsection{Procedure for kinetic model development}

Experiments were conducted at different temperatures, solvent concentrations, enzyme concentrations, solvent loadings, and $\mathrm{CO}_{2}$ partial pressures in the gas phase. It was the aim to develop a consistent model to describe the mass transfer of $\mathrm{CO}_{2}$ by the means of a kinetic model implemented into a mass transfer model with realistic process conditions as input parameters. The influence of enzyme concentration on the enzyme kinetics was determined in a previous 
study [30]. It was concluded that a linear dependency is observed between first order reaction rate constant and enzyme concentration.

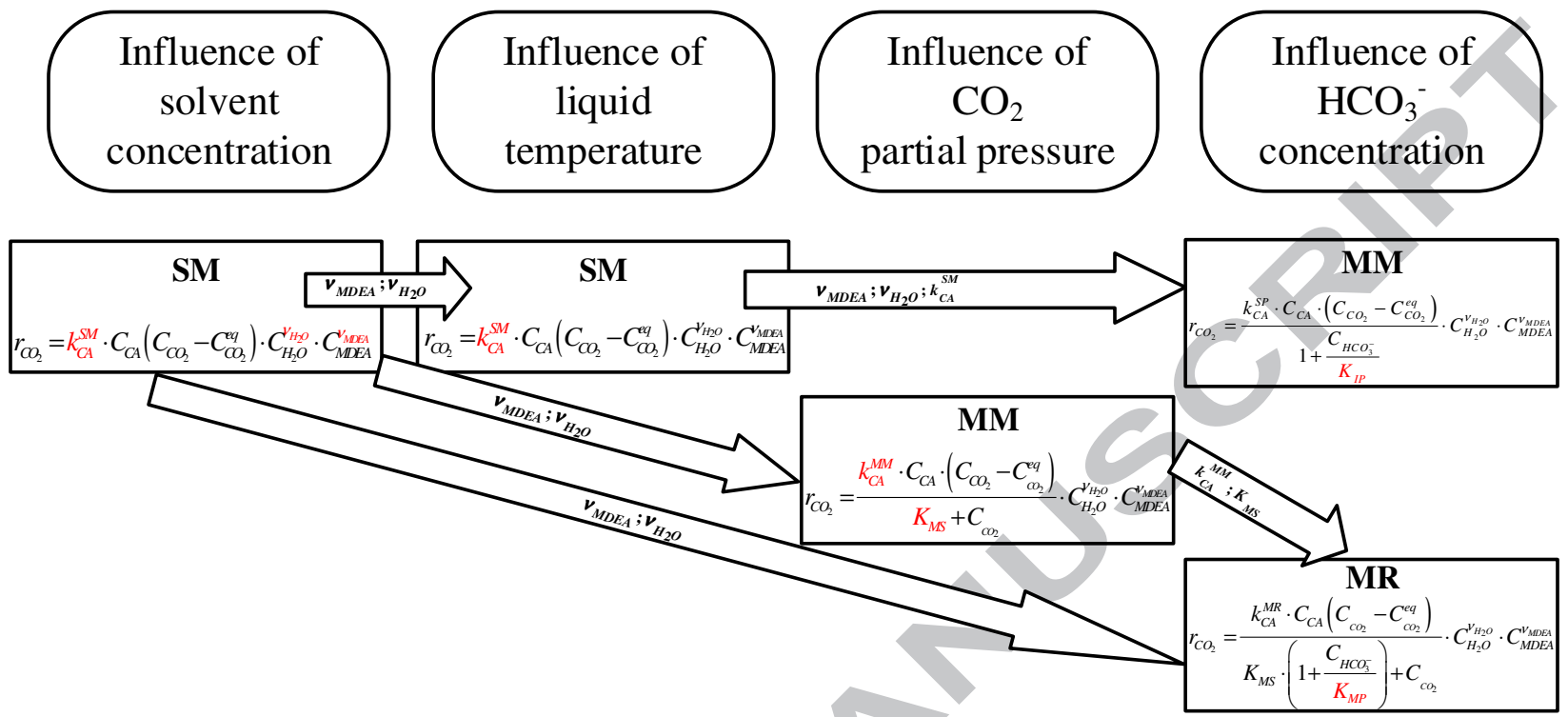

Figure 3: Procedure of the parameter fitting for the different models: the red values were the parameters fitted and the arrows indicate parameter values that have been transferred to other models.

The kinetic models presented in section 2.3 are not direct functions of process temperature or solvent concentration. The parameters in these equation and though might be dependent on temperature or solvent concentration. The described models differ on how the solvent loading, or more precisely the $\mathrm{HCO}_{3}{ }^{-}$concentration, and the interfacial $\mathrm{CO}_{2}$ concentration (linked to the $\mathrm{CO}_{2}$ gas partial pressure via the Henry coefficient) influence the enzyme kinetics.

In the model development a stepwise rather than a global parameter optimization was chosen. Experiments at three different temperatures (298, 313 and $328 \mathrm{~K})$ and three different solvent concentrations $(15,30$ and $50 \mathrm{wt} \%)$ with an enzyme concentration of $0.85 \mathrm{~g} / \mathrm{L}$ were used for the model development, giving a $3 * 3$ matrix. Parameter were optimized around the referencing experimental point $30 \mathrm{wt} \%$ unloaded MDEA at $313 \mathrm{~K}$, The models may in this way describe the 
influence of a certain process condition (temperature, solvent concentration, $\mathrm{HCO}_{3}{ }^{-}$ concentration) while all other process conditions were kept constant.

The influence of solvent concentration on mass transfer was considered first. Experiments with unloaded 15, 30 and $50 \mathrm{wt} \%$ MDEA at $313 \mathrm{~K}$, were taken to derive a correlation for the simple model (Eq. (13)) via nonlinear regression by varying the different powers of the reactants MDEA and water, $v_{M D E A}$ and $v_{H_{2} O}$.

The temperature dependency of the mass transfer was then determined from experiments with unloaded $30 \mathrm{wt} \%$ MDEA at 298, 313 and $328 \mathrm{~K}$ using non-linear regression. This temperature dependency was then tested for the other solvent concentrations, but no fitting was performed.

Afterwards the missing parameters $K_{M S}, K_{M P}$ and $K_{I P}$ for the different model were fitted to experimental data for $30 \mathrm{wt} \%$ MDEA at different $\mathrm{CO}_{2}$ partial pressure or different solvent loadings.

In the end the models were validated against experimental data conducted in the same range of process conditions for different enzyme concentrations. 


\section{Materials and methods}

Mass transfer experiments were conducted in a wetted wall column apparatus with MDEA solvent containing CA. Different solvent concentrations, enzyme concentrations, temperatures solvent loadings and gas $\mathrm{CO}_{2}$ partial pressures were investigated.

\subsection{Chemicals}

N-methyl-diethanolamine (MDEA), obtained from BASF with purity of at least $99 \%$. The chemicals were mixed with de-ionized (DI) water resulting in desired mass fractions of the chemical solvent. Nitrogen and $\mathrm{CO}_{2}$ gas bottles with purities of $99.995 \%$ and $99.99 \%$ resp. from Linde gas were used.

The enzyme carbonic anhydrase (EC 4.2.1.1) used in this study was supplied by Novozymes A/S (Bagsvaerd, Denmark). The enzyme solution was combined with the solvent to provide a total CA concentration between 0 and $3 \mathrm{~g} / \mathrm{l}$ without any additives.

\subsection{Experiments}

The setup used for the mass transfer experiments was a wetted wall column. The configuration as well as the procedure was in detail discussed in our previous work [30]. The difference in this study was that we used loaded solvents. $\mathrm{BaCl}_{2}$ titration experiments were performed to determine the loading of the solvents, the procedure for this titration was taken from Sønderby et al. [31].

Density and viscosity of these samples was also determined to investigate the effect of enzyme addition on these physical properties and account for the changes. The density of the solution was determined with a DMA 230 Anton Parr with an accuracy of $\pm 0.0001 \mathrm{~g} \mathrm{~cm}^{-3}$. A rotating ball viscosimeter Paar AMV 220 was used for viscosity measurements with a $1.6 \mathrm{~mm}$ glass capillary and a metal ball with the density of $7.65 \mathrm{~g} \mathrm{~cm}^{-3}$, DI water was taken as a reference; the accuracy of these measurements were $\pm 0.01 \mathrm{mPa}$. 
The amount of experiments used for model validation for the different setpoints is listed in Table 3. The high number of experiments results from the determination method of the mass transfer coefficient in the wetted wall column; several experimental points were needed for the linear regression of the mass transfer coefficient as shown in Figure 4.

Table 3: Number of experiments at different process conditions used for model validation

\begin{tabular}{l|lll|l}
\hline & $15 \mathrm{wt} \%$ & $30 \mathrm{wt} \%$ & $50 \mathrm{wt} \%$ & total \\
\hline $298 \mathrm{~K}$ & 10 & 86 & 8 & 104 \\
$313 \mathrm{~K}$ & 11 & 115 & 7 & 133 \\
$328 \mathrm{~K}$ & 12 & 63 & 11 & 86 \\
\hline total & 33 & 264 & 26 & 323
\end{tabular}

\subsection{Physical properties of the solvents}

In order to solve the Enhancement factor, the Hatta number for that reaction needs to be calculated. Ha correlates the maximum conversion through reaction compared to the maximum transport due to physical diffusion. Ha can be calculated if the diffusivity of $\mathrm{CO}_{2} D_{\mathrm{CO}_{2}}^{S O l}\left(\mathrm{~m}^{2} \mathrm{~s}^{-1}\right)$ in that solvent is known. As $\mathrm{CO}_{2}$ reacts with the solvent it is impossible to measure the pure diffusion of $\mathrm{CO}_{2}$. In order to gather diffusion parameters from absorption experiments models are needed that also include certain assumptions. A widespread method is the use of the " $\mathrm{N}_{2} \mathrm{O}$ Analogy" to estimate diffusion parameters [23]. In this approach the diffusion of $\mathrm{N}_{2} \mathrm{O}$, a molecule that does not react with the solvent but shows structural similarity, is measured under the desired conditions. The diffusion coefficient can be then estimated according to: 
$D_{\mathrm{CO}_{2}}^{\text {sol }}=\frac{D_{\mathrm{CO}_{2}}^{\mathrm{H}_{2} \mathrm{O}}}{D_{\mathrm{N}_{2} \mathrm{O}}^{\mathrm{H}_{2} \mathrm{O}}} D_{\mathrm{N}_{2} \mathrm{O}}^{\mathrm{sol}}$

With $D_{\mathrm{N}_{2} \mathrm{O}}^{\mathrm{H}_{2} \mathrm{O}}$ and $D_{\mathrm{CO}_{2}}^{\mathrm{H}_{2} \mathrm{O}}$ being the diffusion coefficient $\left(\mathrm{m}^{2} \mathrm{~s}^{-1}\right)$ of $\mathrm{N}_{2} \mathrm{O}$ and $\mathrm{CO}_{2}$ in pure water that can be taken from literature; $D_{\mathrm{N}_{2} \mathrm{O}}^{\mathrm{SO}}$ is the diffusion coefficient of $\mathrm{N}_{2} \mathrm{O}$ measured in the solvent.

In our experiments $D_{\mathrm{CO}_{2}}^{\mathrm{SO}_{2}}$ was calculated according to Eq. (32), using a correlation for $D_{\mathrm{N}_{2} \mathrm{O}}^{\mathrm{H}_{2} \mathrm{O}}$ and $D_{\mathrm{CO}_{2}}^{\mathrm{H}_{2} \mathrm{O}}$ from Versteeg [23] and $D_{\mathrm{N}_{2} \mathrm{O}}^{\mathrm{Sol}}$ for MDEA from Ko et al. (2001)[32].

The correlation for the Henry coefficient for $\mathrm{CO}_{2} \mathrm{H}_{\mathrm{CO}_{2}}\left(\mathrm{~Pa} \mathrm{~m}^{3}\right.$ mole $\left.{ }^{-1}\right)$ was taken from Versteeg et al. [23].It was assumed that the addition of CA enzymes would not change the solubility of the solvents, as $\mathrm{N}_{2} \mathrm{O}$ experiments with $\mathrm{CA}$ did not show any effect on the solubility in the work of Penders-van Elk (2012)[10].

\subsection{Liquid phase composition}

The composition of the liquid phase and the corresponding concentrations of the different ions in solution were derived from an extended UNIQUAC thermodynamic model for MDEA[33]. The partial pressure in the gas phase was changed to several setpoints during an experimental run, this resulted in a linear relationship between gas partial pressure and mass transfer of $\mathrm{CO}_{2}$ in the pseudo first order reaction regime. An example of an experimental result from the wetted wall column is shown in Figure 4.

The fitting line for these experimental points is crossing the $\mathrm{x}$-axis for loaded solvents with desorption on experiments with gas partial pressure lower than the intersection and absorption on gas partial pressures higher than the intersection. 
This intersection represents the partial pressure of $\mathrm{CO}_{2}$ in the gas phase where no mass transfer occurs and can be treated as the experimentally determined equilibrium partial pressure $P_{\mathrm{CO}_{2}}^{e q}$ of the liquid phase.

It is important to use the experimental points in the linear range for the determination of $P_{\mathrm{CO}_{2}}^{e q}$. When experiments are conducted outside of pseudo first order regime, which is the case for very high $\mathrm{CO}_{2}$ gas partial pressures, then the correlation between gas partial pressure and mass transfer flux becomes non-linear and a regression through the experimental points cannot be done. We considered a maximum $\mathrm{CO}_{2}$ gas partial pressure of $20 \mathrm{kPa}$ for the determination of $P_{\mathrm{CO}_{2}}^{e q}$, all experimental above were neglected.

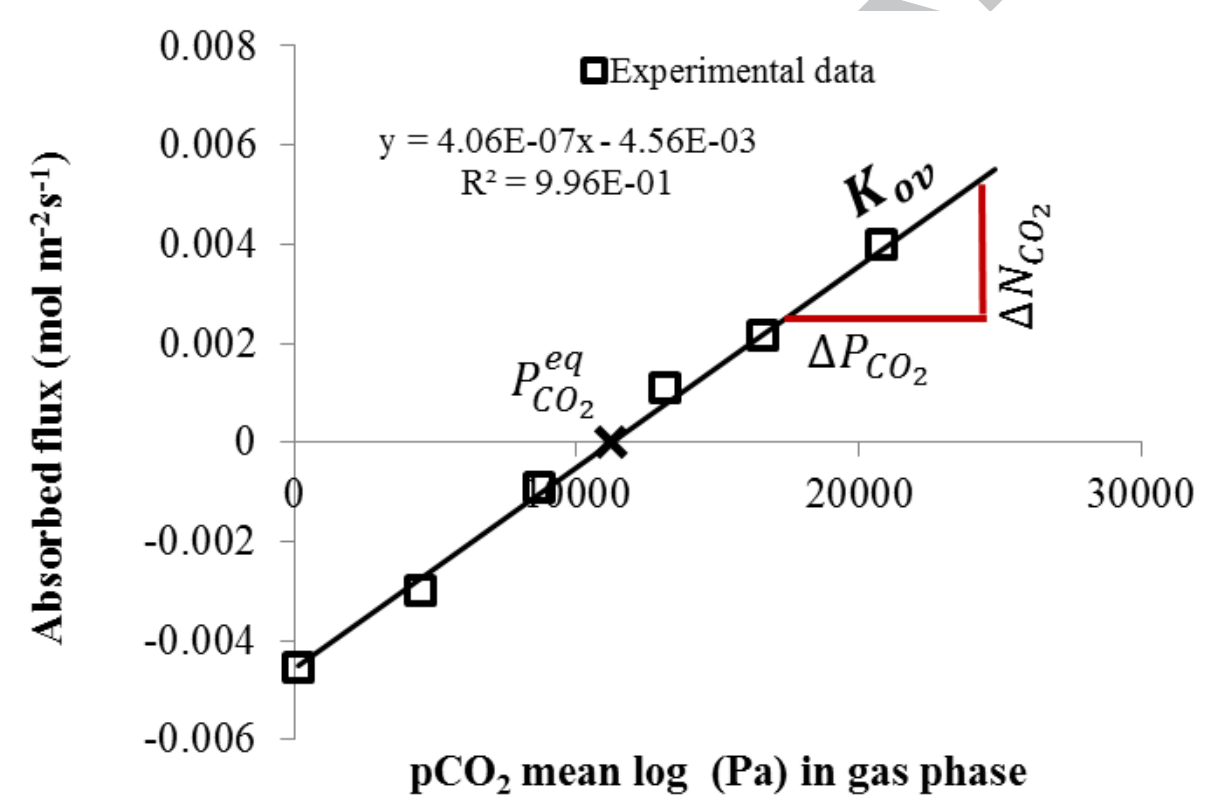

Figure 4: Determination method of the overall mass transfer coefficient from the experimental results of the wetted wall column 


\section{Results and discussion}

\subsection{Model development}

The mass transfer of $\mathrm{CO}_{2}$ was measured with MDEA in a wetted wall column apparatus and the liquid side mass transfer coefficient was calculated as described in our previous study [30]. The model for CA enhanced MDEA was derived from experiments describing the influence of solvent concentration, enzyme concentration, solvent temperature, $\mathrm{CO}_{2}$ partial pressure and solvent loading. The model was developed step by step by changing one process condition at a time and modifying model descriptions to account for the influence of the specific process condition on the liquid side mass transfer coefficient. Each variable is described below.

\subsubsection{Influence of solvent concentration on mass transfer}

The liquid side mass transfer coefficient of CA enhanced MDEA at $313 \mathrm{~K}$ is steadily dropping if the MDEA concentration is increased from 15 over 30 to $50 \mathrm{wt} \%$ as shown in Figure 5. For the correlation of the liquid side mass transfer the SM (Eq. (13)) model was chosen with different powers of the reactants water and MDEA as in Eq. (31) and $k_{C A}^{S M}$ was fitted to match the experiment at $30 \mathrm{wt} \%$ MDEA and $313 \mathrm{~K}$. The results are shown in Figure 5, the naming of the different curves express the power of each reactant, e.g. $w^{1} s^{1}$ means water (w) as well as the solvent (s) has the power 1 in Eq. (31). Taking the simplest expression with no power in water and MDEA $\left(w^{0}\right)$ does not result in a satisfying correlation; even though the trend is the same as the experiments, the correlation under-predicts the liquid side mass transfer for low solvent concentrations and over-predicts for higher conditions.

The solvent concentration of MDEA does not influence reaction mechanism of carbonic anhydrase directly, as in both cases when solvent concentration was considered in the reaction rate $\left(w^{1} s^{1}\right.$ and $\left.s^{1}\right)$ the simulated liquid side mass transfer coefficient showed a different trend 
than the experimental results. Once the power of the water concentration is increased, the simulated correlations for $\mathrm{k}_{\text {liq }}$ gets closer to the experiments. From our experiments a power of 2 on the water concentration is suitable.

The influence of MDEA concentration on the kinetics of CA has been previously investigated by Penders-van Elk et al. [10]. They came to the same conclusion, that MDEA does not directly influence the kinetics of CA and suggested the power of the water concentration should be 1 in the reaction rate. The difference between our results might arise from the fact that we used different enzymes in our experiments. Considering that the rate limiting step in the enzyme reaction mechanism is the intramolecular proton transfer from the zinc bound water to the proton channel PC (picture D in Figure 1) which occurs via a network of hydrogen bonded water molecules can explain why the power of the water concentration might be higher than one, in our case. 


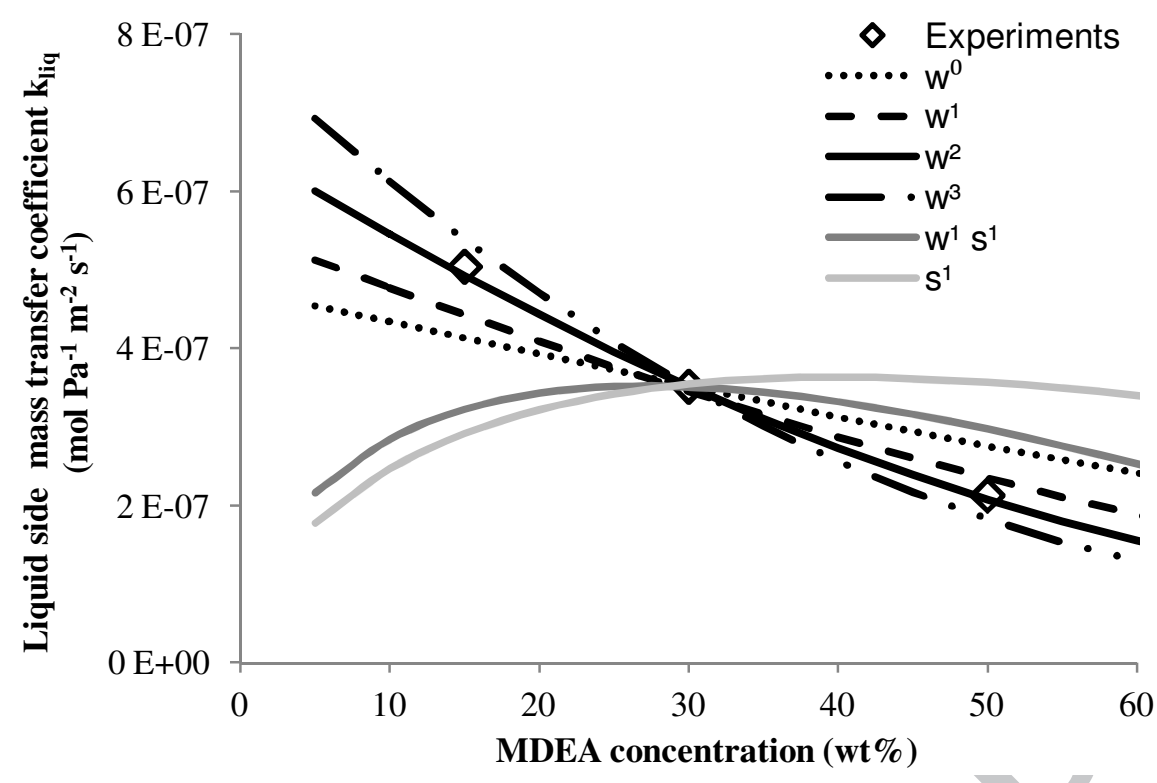

Figure 5: Influence of solvent concentration on the liquid side mass transfer coefficient at $313 \mathrm{~K}$ : comparison of different powers on the reactants MDEA (s) and $\mathrm{H}_{2} \mathrm{O}(\mathrm{w}$ ) in the enzyme kinetics on the mass transfer model of CA enhanced MDEA

\subsubsection{Influence of temperature on mass transfer}

The liquid side mass transfer coefficient is decreasing with temperature for 15 and 30 wt $\%$ MDEA concentration; the decrease is more distinct for a lower concentration. For $50 \mathrm{wt} \%$ the liquid side mass transfer coefficient $\mathrm{k}_{\text {liq }}$ remains almost constant over the temperature range between 298 and $328 \mathrm{~K}$. Using the correlation as well as the $k_{C A}^{S M}$ value derived in the section 5.1.1 without any temperature adjustment to $k_{C A}^{S M}$, results in very good agreement between the mass transfer model and the experimental data, as shown in Figure 6. This would indicate that the kinetic rate constant for the $\mathrm{CA}$ is not temperature dependent in the range between 298 and 328 $\mathrm{K}$.

Some researchers found an increase in CA reaction rate constant with temperature, for MDEA [17] and $\mathrm{K}_{2} \mathrm{CO}_{3}$ [19], whereas others observed no change in $\mathrm{K}_{2} \mathrm{CO}_{3}$ [18]. In our previous study we even reported a decrease in kinetic rate constant with temperature for a different CA in 
MDEA [30]. It is important to note, that the purpose of all these experiments was to derive correlations for $\mathrm{CA}$ kinetics to describe the mass transfer of $\mathrm{CO}_{2}$. As the liquid side mass transfer is dependent on the solubility of the $\mathrm{CO}_{2}\left(\mathrm{H}_{\mathrm{CO}_{2}}\right)$, the diffusivity of $\mathrm{CO}_{2}\left(\mathrm{D}_{\mathrm{CO}_{2}}\right)$ in the solution as well as the reaction rate with $\mathrm{CO}_{2}$, the value and temperature dependency of the reaction rate constant for CA relies on the literature value of solubility and diffusivity as well their temperature dependency. When using a kinetic reaction constant from literature it is important to use it together with the solubility and diffusivity from that same source.

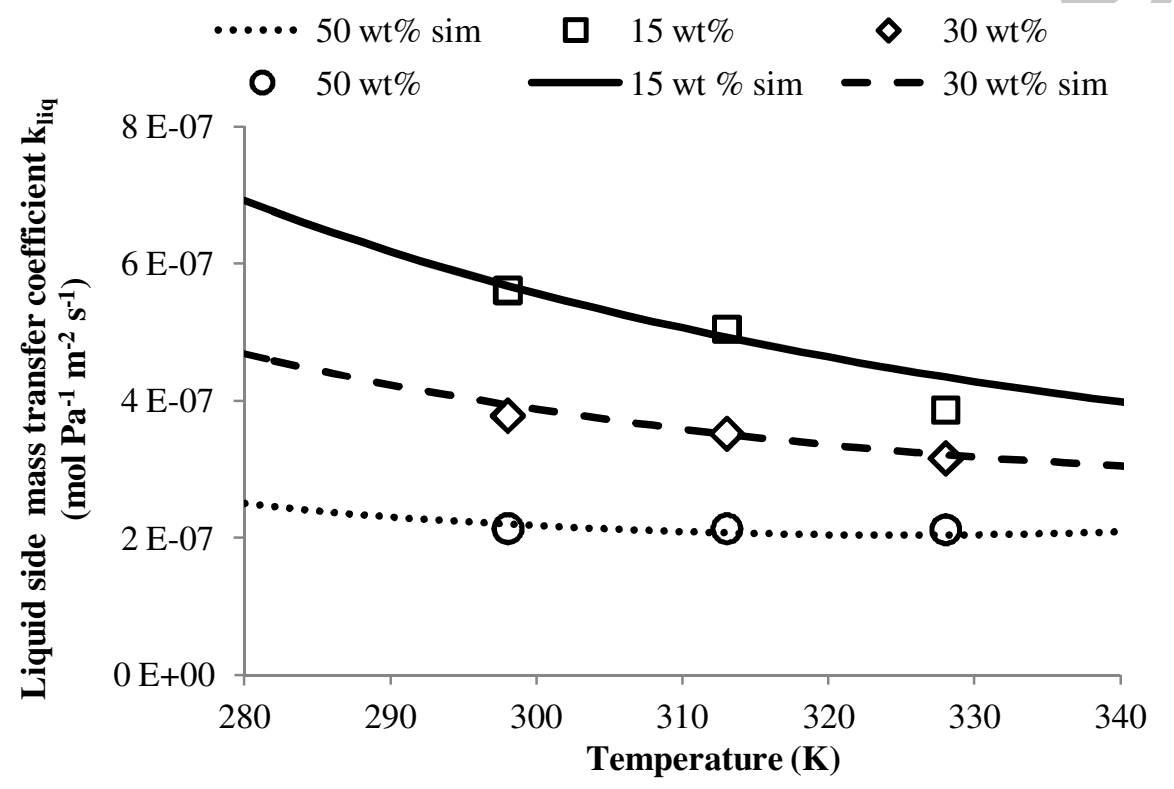

Figure 6: Influence of process temperature on the liquid side mass transfer coefficient for different MDEA concentrations (15, 30 and $50 \mathrm{wt} \%)$ : Comparison between experiments and simple enzyme model (SM) with a reaction rate dependency of water with the power of two.

5.1.3. Influence of $\mathrm{CO}_{2}$ partial pressure on the mass transfer 
When performing experiments at higher partial pressure of $\mathrm{CO}_{2}$ a slight decrease $\mathrm{k}_{\text {liq }}$ could be observed in Figure 7. This effect is unlikely caused by a depletion of a reactant near the interface as CA reacts with water which is abundant in the solution. The rate limiting step at high buffer concentrations is the intramolecular proton transfer and not deprotonation to a buffer in solution.

A possible explanation for this behavior is substrate saturation of $\mathrm{CO}_{2}$. CA is known to follow Michaelis Menten type reaction kinetics [34]. The Michaelis Menten constant $K_{M S}$, gets neglected in most applications of CA in CCS solvents on $\mathrm{CO}_{2}$ capture from coal power plant. The reason being the low partial pressure of $\mathrm{CO}_{2}$, leading to $\mathrm{CO}_{2}$ liquid concentrations an order of magnitude lower than the Michaelis Menten constant. Under these conditions the simplification described in Eq. (13) might be applied. Hu et al. [19] and Mirjafari et al. [35] determined the $K_{M S}$ value for $\mathrm{CA}$ in $\mathrm{K}_{2} \mathrm{CO}_{3}$ and $\mathrm{CaCO}_{3}$ respectively; They reported values of 12.5 and $17.8 \mathrm{~mole} \mathrm{~m}^{-3}$. Taking a $K_{M S}$ value of 15 mole $\mathrm{m}^{-3}$ and refitting $k_{C A}^{M M}$ that $\mathrm{k}_{\text {liq }}$ for $30 \mathrm{wt} \%$ MDEA at $313 \mathrm{~K}$ matches, when the $\mathrm{CO}_{2}$ partial pressure in the gas is about $7.5 \mathrm{kPa}$ (approximate arithmetic mean partial pressure of $\mathrm{CO}_{2}$ in the column considering $15 \mathrm{kPa}$ inlet $\mathrm{CO}_{2}$ partial pressure and no $\mathrm{CO}_{2}$ outlet partial) gives the MM model, which incorporates Michaelis Menten type behavior.

The experimental data here is a bit scattered since all data points are derived from one single experiment, since all experimental data points come from one single experiment. Other $\mathrm{k}_{\text {liq }}$ values were derived from 5 different $\mathrm{CO}_{2}$ partial pressures.

The SM model, as it does not incorporate any influence of the $\mathrm{CO}_{2}$ concentration on the liquid side mass transfer coefficient is not changing at higher $\mathrm{CO}_{2}$ gas partial pressures, which is in disagreement with the experiments.

The MM model that describes the influence of $\mathrm{CO}_{2}$ concentration on the mass transfer through the Michalis Menten constant $K_{M S}$, matches the trend of the experimental data quite well for 298 
and $328 \mathrm{~K}$. Even though the SM model is not describing the trend of the liquid side mass transfer coefficient in the range between 0 and $50 \mathrm{kPa}$, in the region of low pCO2 (<15 $\mathrm{kPa})$ typically encountered in CCS applications for coalfired power plants, the differences between the SM and MM model are quite small. This indicates, that models that don't account for the influence of $\mathrm{CO}_{2}$ partial pressure and thus $\mathrm{CO}_{2}$ concentration in the liquid phase can be used for low $\mathrm{CO}_{2}$ partial pressure applications. For application with a $\mathrm{CO}_{2}$ partial pressure higher than $15 \mathrm{kPa}$ it is advised to use models that incorporate the Michalis Menten kinetics and describe the effect $\mathrm{CO}_{2}$ partial pressure influence, otherwise the mass transfer parameter will be overestimated.

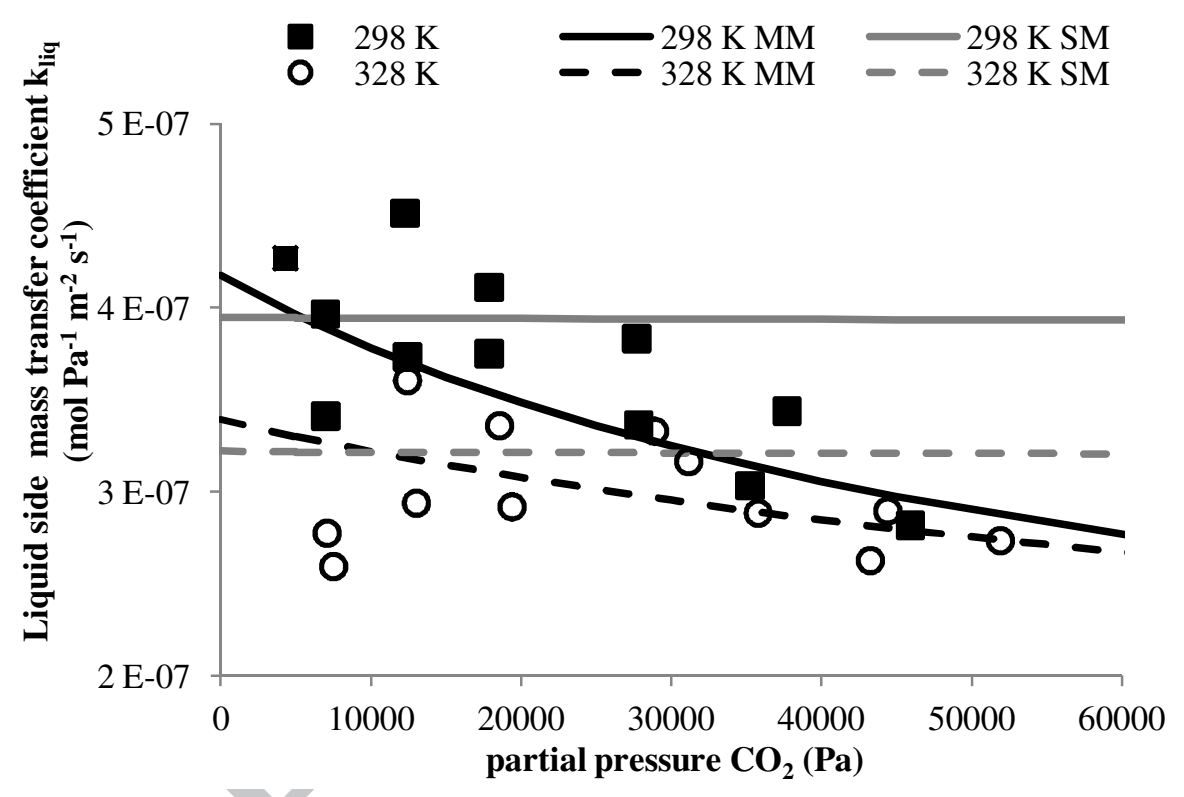

Figure 7: Influence of partial pressure of $\mathrm{CO}_{2}$ in gas phase on liquid side mass transfer coefficient for 298 and $328 \mathrm{~K}$ : Comparison of models neglecting (SM) and incorporating Michaelis Menten kinetics for the forward reaction (MM).

\subsubsection{Influence of solvent loading on mass transfer}

Similar to the procedure for $\mathrm{CO}_{2}$ partial pressure dependency, new models are introduced to describe the dependency of solvent loading on the liquid side mass transfer coefficient, namely the SP model (Eq. (14)), an extension of the SM model with an introduced product inhibition 
term for the bicarbonate ion, and the MR model (Eq. (11)), a Michaelis Menten mechanism for reversible reactions and thus a combination of the MM and SP model. For the SP model the $k_{C A}^{S P}$ value was taken from the SM model $\left(k_{C A}^{S M}\right)$, for the MR model the value for $k_{C A}^{M R}$ was taken from $k_{C A}^{M M}$ and the $K_{M S}$ was the same as in the MM model. For both models just the $K_{I P}$ and $K_{M S}$ values were fitted to match the experimentally determined kliq for $30 \mathrm{wt} \%$ MDEA at $313 \mathrm{~K}$ at different solvent loadings shown in Figure 8.

The liquid side mass transfer coefficient is decreasing at higher solvent loadings. A probable explanation for that behavior is a product saturation, where the bicarbonate product is occupying the active site of the enzymes at higher concentration and decreasing the reaction rates. The trend of decrease in kliq with higher $\mathrm{CO}_{2}$ loading is very well described with The SP and MR model, assuming a $\mathrm{CO}_{2}$ partial pressure of $\mathrm{CO}_{2}$ in the absorber of $7.5 \mathrm{kPa}$ for the $\mathrm{MR}$ model. Both models are overlapping with each other over the whole range, the same goes for the MM and SM model, but these models do not describe the trend of decreasing $\mathrm{k}_{\text {liq }}$ at higher loading and are over-predicting the liquid side mass transfer coefficient, once the solvent is slightly loaded. A proper mass transfer model needs to account for the change in $\mathrm{k}_{\text {liq }}$ with loading to yield accurate predictions, as it is inevitable that the loading changes inside the absorber. The SM and MM model are therefore not suitable for use in absorber column modelling, unless it is experimentally proven that the $\mathrm{k}_{\text {liq }}$ is not influenced by solvent loading. 


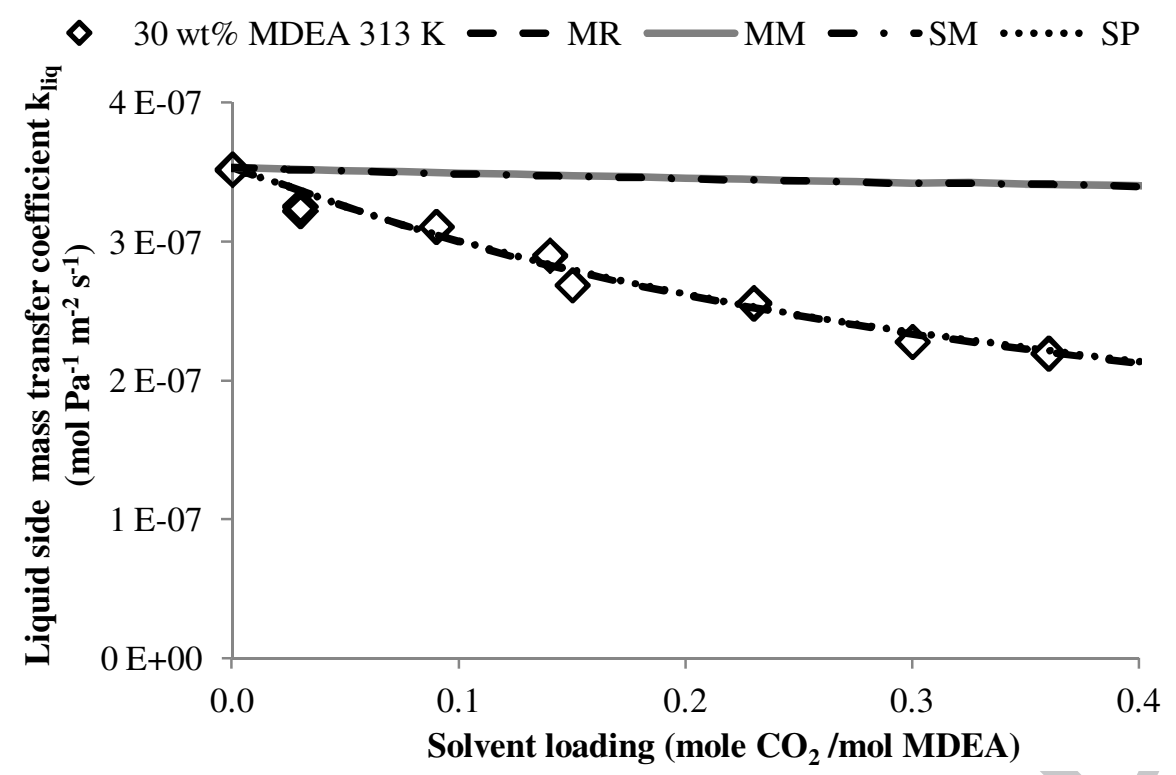

Figure 8: Influence of solvent loading on the liquid side mass transfer coefficient for $30 \mathrm{wt} \%$ MDEA at $313 \mathrm{~K}$; Comparison of models neglecting (SM, MM) and incorporating influence of the bicarbonate ion on the reaction rate.

The SP and MR model can accurately predict the decrease in kliq for $30 \mathrm{wt} \%$ MDEA at 298 and $328 \mathrm{~K}$ at higher solvent loadings as shown in Figure 8. No temperature depended adjustment to $K_{I P}$ and $K_{M S}$ was needed. Both correlations are only slightly over predicting the experimental data, which can be explained with the fact, that model is slightly over predicting the liquid side mass transfer coefficient at $298 \mathrm{~K}$ and $328 \mathrm{~K}$ for unloaded solvent as shown in Figure 6 . These deviations are quite small, and no obvious trend is noticeable. 


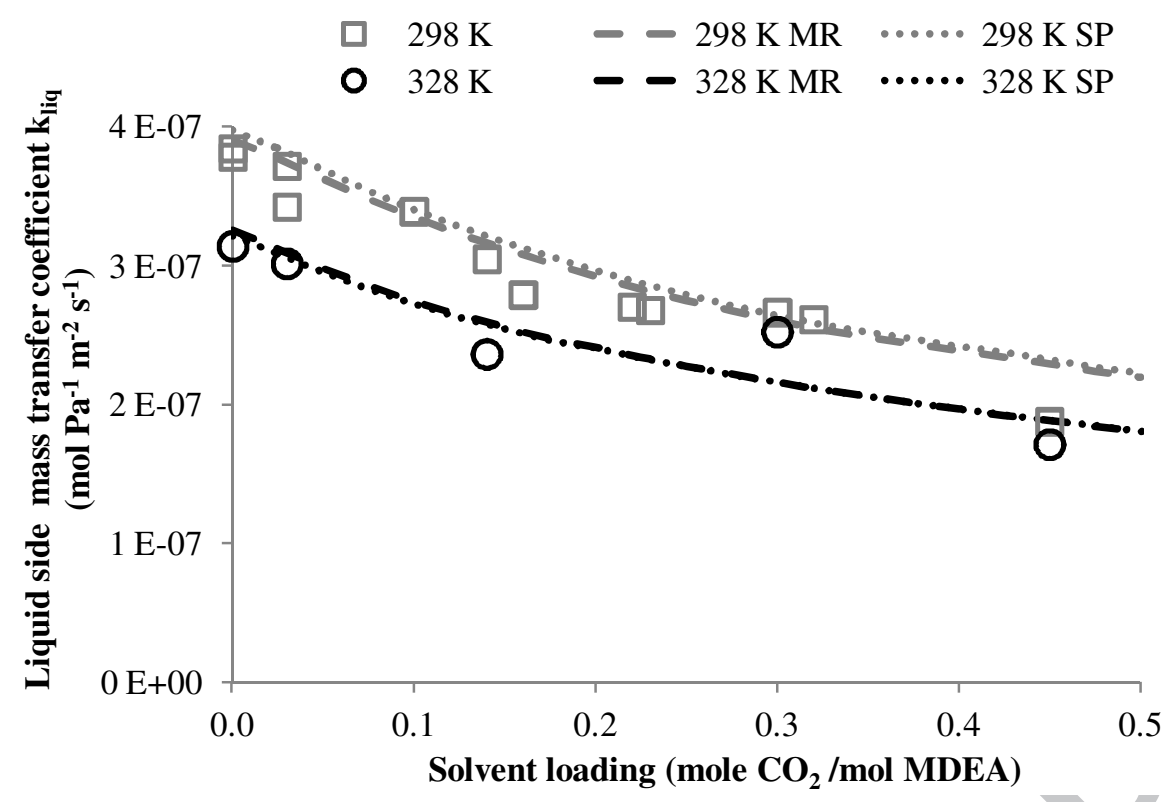

Figure 9: Influence of Solvent loading on liquid side mass transfer coefficient for $30 \mathrm{wt} \%$ MDEA at 298 and $328 \mathrm{~K}$.

Even for different solvent concentrations these models can be used to describe the mass transfer at higher loadings. The results for $\mathrm{k}_{\mathrm{liq}}$ in 15 and $50 \mathrm{wt} \%$ MDEA at $313 \mathrm{~K}$ is shown in Figure 10. Both models give almost identical results and are capable of describing the trend of the experiments. The inhibition term in the SP model and the reverse reaction term in the MR model are indirectly linked to the solvent loading, as these terms are influenced by the bicarbonate ion concentration, which is dependent also on the solvent concentration. The bicarbonate concentration of a solvent with $50 \mathrm{wt} \%$ MDEA is about 3.5 times higher than for a solvent with $15 \mathrm{wt} \%$ at the same loading. The SP and MR model are capable of predicting the liquid side mass transfer coefficient as function of bicarbonate concentration incorporating basic enzyme mechanisms for different temperatures as well as solvent concentrations in a broad range of solvent loading, therefore the suggested enzyme mechanism behind, is suitable for describing the mass transfer in CA enhanced MDEA. 


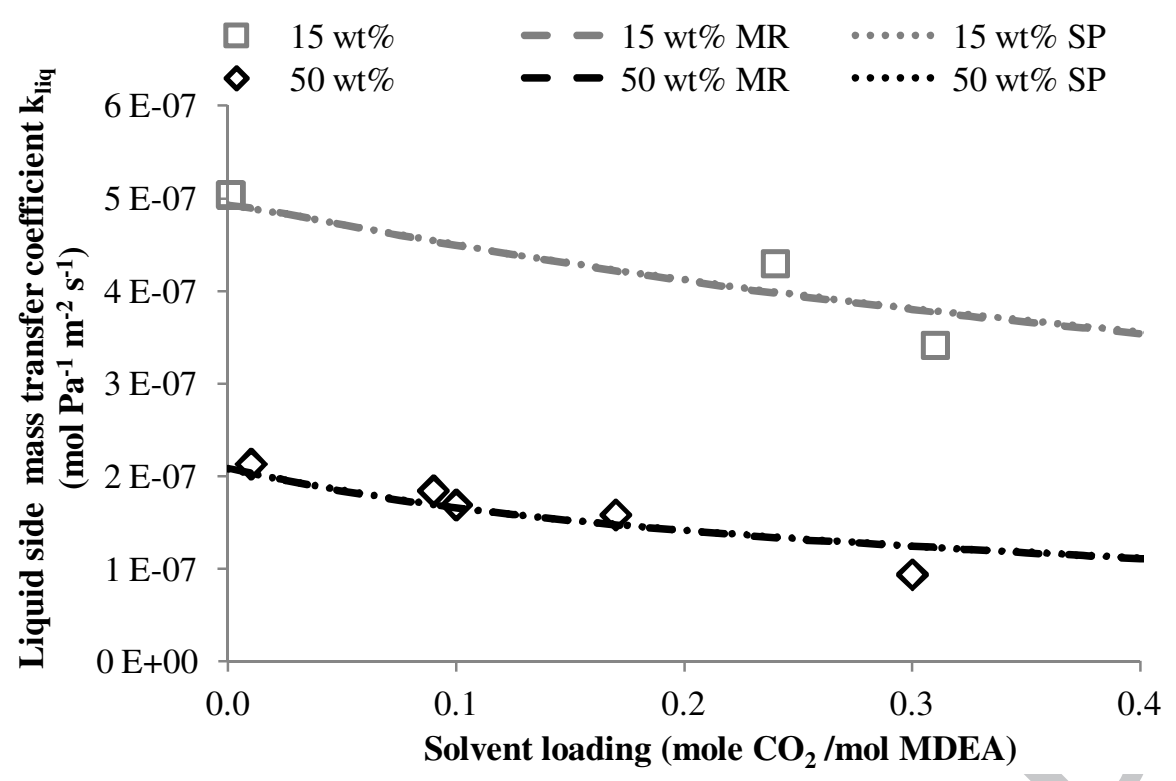

Figure 10: Influence of solvent loading on mass transfer for $15 \mathrm{wt} \%$ and $50 \mathrm{wt} \%$ MDEA at 313K: Comparison between experimental data and MR model

\subsubsection{Influence of enzyme concentration on mass transfer}

The enzyme concentrations is a crucial process parameter, as more enzymes will result in higher mass transfer, but at the same time also increase the costs. The influence of enzyme concentration on the liquid side mass transfer coefficient together with the model predictions are shown in Figure 11 . The model is capable of predicting the $\mathrm{k}_{\text {liq }}$ fairly well, up to an enzyme concentration of $3 \mathrm{~g} / \mathrm{L}$. At very high concentrations the model over-predicts the mass transfer by $15 \%$. The model assumes a linear relationship between enzyme reaction rate and enzyme concentration, which seems to be valid for low concentrations. Several authors reported a deviation from that linear relationship at high enzyme concentrations [10][36][37]. Pender-van Elk et al. proposed a Langmuir-Hinshelwood type of relation as in Eq. (17) to describe that behavior. Using that expression and keeping the $k_{C A}^{S P}$ value in the numerator as $k_{3}^{*}$ and adjusting just the $k_{4}^{*}$ value, we could fit the trend very well. In that case the SP model was used, but all other gave identical results and could be used with the same derived $k_{4}^{*}$ value. The Langmuir Hinshelwood expression was not used for model validation, as the experiments were performed at $0-3 \mathrm{~g} / \mathrm{L} \mathrm{CA}$ and in that 
region both correlations do not differ too much. Besides that we do not see a mechanistic explanation for using a Langmuir Hinshelwood type relation.

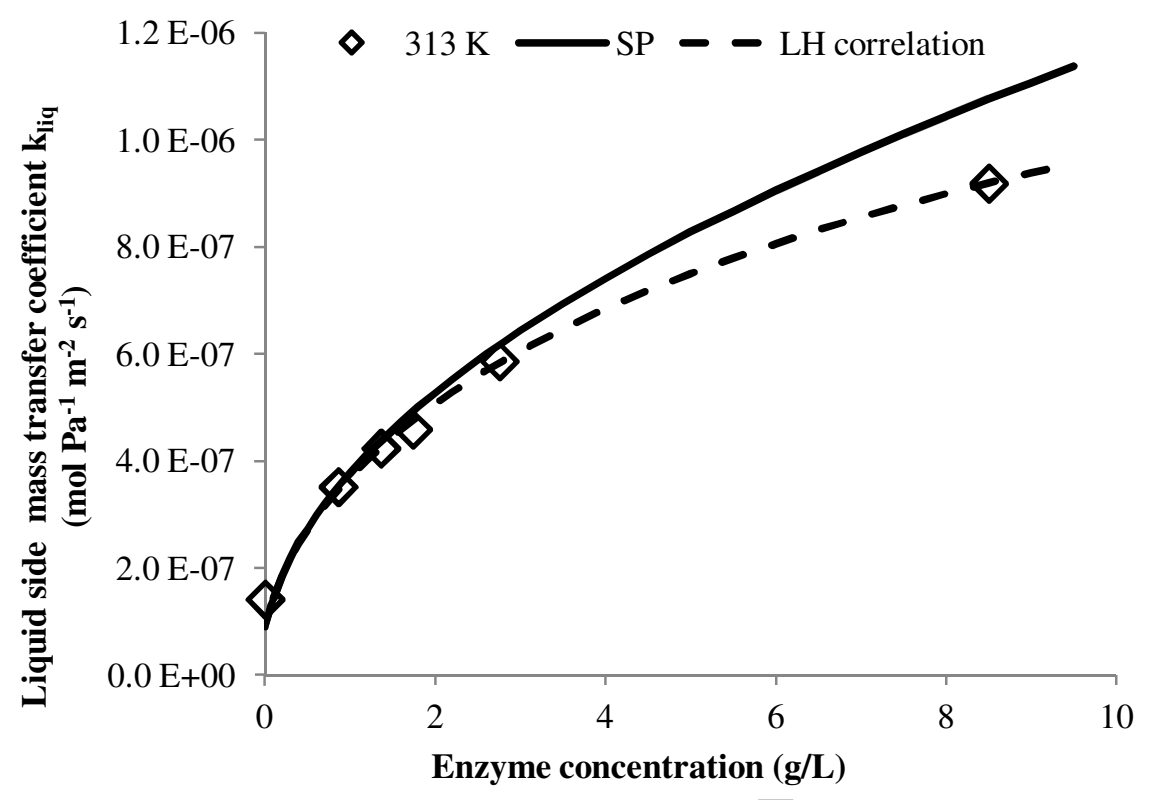

Figure 11: Influence of enzyme concentration on liquid side mass transfer coefficient for $30 \mathrm{wt} \%$ MDEA at $313 \mathrm{~K}$ : Comparison of experimental data, SP model and SP model with Langmuir Hinshelwood type of dependency on the enzyme concentration.

\subsection{Model validation}

The kinetic constants for the different models are summarized in Table 4, the reaction rate can be expressed as:

$r_{\mathrm{CO}_{2}}^{e n z}=r_{e n z} \cdot C_{\mathrm{H}_{2} \mathrm{O}}^{2}$

With $r_{e n z}$ being the one of the discussed enzyme model, SM, SP, MM or MR described in Eq. (11)-(14). Some of the kinetic constants are the same, as the some models are extension of others. 
Table 4: Kinetic constants for the different models

\begin{tabular}{|c|c|c|c|c|c|c|}
\hline & 1. & $\mathrm{~V}$ & 2. & $\mathrm{~V}$ & 3. & $\mathrm{~V}$ \\
\hline & & & & mole $\mathrm{m}^{-3}$ & & mole $\mathrm{m}^{-3}$ \\
\hline SM & $k_{C A}^{S M}$ & $1.05 \mathrm{E}-06$ & & & & \\
\hline SP & $\boldsymbol{k}_{\boldsymbol{C A}}^{S P}$ & $1.05 \mathrm{E}-06$ & $K_{I P}$ & $5.05 \mathrm{E}+02$ & & \\
\hline MM & $k_{C A}^{M M}$ & $1.77 \mathrm{E}-05$ & & & $K_{M S}$ & $1.50 \mathrm{E}+01$ \\
\hline MR & $k_{C A}^{M R}$ & $1.77 \mathrm{E}-05$ & $K_{M P}$ & $4.40 \mathrm{E}+02$ & $K_{M S}$ & \\
\hline
\end{tabular}

The model was validated against 323 experiments; of which $23 \%$ (74 total) were desorption experiments and $77 \%$ were absorption experiments. The average absolute relative deviation AARD (\%) was calculated from the experimental and the modelled flux according to:

$A A R D(\%)=\frac{1}{n} \sum \frac{\left|N_{C_{2}}^{e x p}-N_{C O_{2}}^{\text {model }}\right|}{N_{C O_{2}}^{e x p}}$

The performance of the different models is shown in Table 5, where the mean relative deviation of the experiments and models are listed. The best model prediction is given by the complex MR model, where the ARD was $14 \%$ and the absorption experiments could be described with an accuracy of $12 \%$, whereas the model had $23 \%$ accuracy for desorption.

The second best model was the SP, which neglected the Michaelis Menten behavior for $\mathrm{CO}_{2}$, but incorporated a product inhibition by the bicarbonate. It had a slightly worse performance overall (15 vs.14\%) and for absorption (13 vs $12 \%)$; it could though predict desorption slightly better.

The models which did not account for influence of solvent loading on the liquid side mass transfer coefficient, the MM and SM model, performed much worse. This shows that the 
influence of the bicarbonate ion is more important for the mass transfer model than the substrate saturation of $\mathrm{CO}_{2}$.

Over $90 \%$ of the experiments were carried out at partial pressures of $\mathrm{CO}_{2}$ below $30 \mathrm{kPa}$ this explains why the accuracy of the MR model and SP model are comparable. It also justifies the use of the simplified SP model for absorber columns with low $\mathrm{CO}_{2}$ gas partial pressure like in CCS applications for coal burning power plants.

Table 5: Average absolute relative deviation for the different models

\begin{tabular}{|c|c|c|c|}
\hline & total & absorption & desorption \\
\hline $\begin{array}{l}\text { Number of } \\
\text { experiments }\end{array}$ & 323 & 249 & 74 \\
\hline SM & $38 \%$ & $30 \%$ & $65 \%$ \\
\hline $\mathrm{SP}$ & $15 \%$ & $13 \%$ & $22 \%$ \\
\hline MM & $33 \%$ & $24 \%$ & $64 \%$ \\
\hline MR & $14 \%$ & $12 \%$ & $23 \%$ \\
\hline
\end{tabular}

The parity plots for the SP and MR model are shown in Figure 12. The upper row shows parity plots distinguishing between the different solvent concentration and lower row distinguishing between the different temperatures. Both models are predicting the mass transfer of $\mathrm{CO}_{2}$ fairly well for absorption and desorption. From that plots it can be seen, that the SP model tends to over-predict the mass transfer at higher fluxes. The high $\mathrm{CO}_{2}$ fluxes are just for $30 \mathrm{wt} \% \mathrm{MDEA}$, because most experiments with higher enzyme concentration were carried out with 30 wt $\%$ MDEA.

The temperature dependency is well described for the SP model, no systematic deviation between experiments and simulation is visible. The MR model eliminates the trend of over-predicting the absorption for higher fluxes. The difference in desorption modeling between these two models is marginal. 


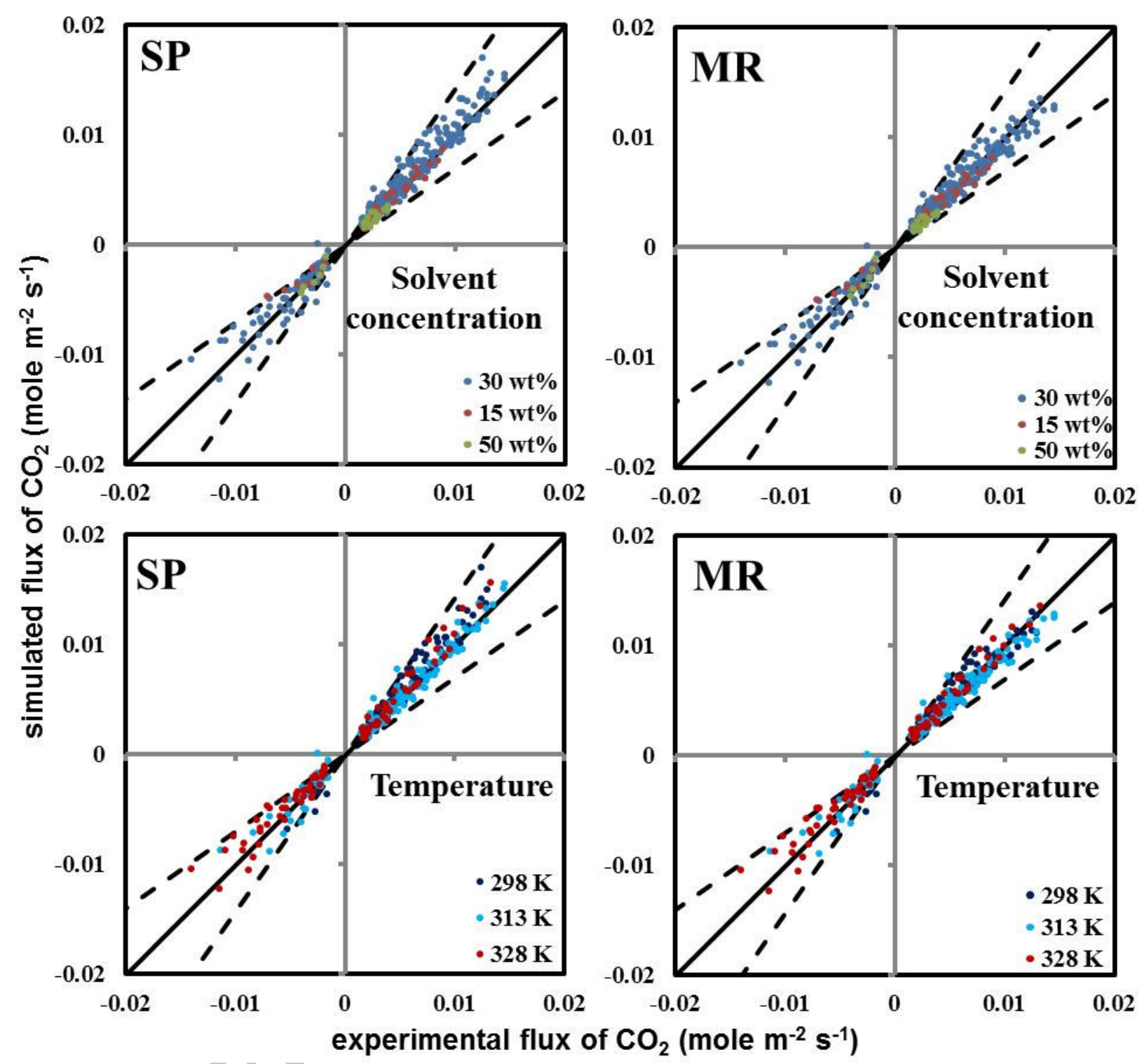

Figure 12: Parity plot for the SP and MR model validation, dashed lines indicate $\pm 30 \%$ deviation. The experiments were conducted at different enzyme concentrations ranging from 0.9$2.7 \mathrm{~g} / \mathrm{L}$. 


\section{Conclusion}

Kinetic models for the enzyme carbonic anhydrase in aqueous MDEA solutions were derived using mechanistic correlations. These models were tested on their performance to predict the mass transfer of 323 experiments at different solvent concentrations, solvent temperatures, $\mathrm{CO}_{2}$ partial pressures, solvent loadings and enzyme concentrations.

Four different models were presented and compared: one simple model (SM), where the reaction rate was just dependent on the $\mathrm{CO}_{2}$, water and enzyme concentration. The simple model was extended, to incorporate substrate saturation according to Michaelis Menten kinetics (MM model), or extended to account for product inhibition by the bicarbonate ion (SP model). One advanced model that considered as well substrate saturation as product saturation for reversible reactions (MR) was also tested.

Based on the observations, the $\mathrm{CA}$ reaction rate is dependent on the water concentration with the power of two. The CA reaction rate did not change at different temperatures in the range of 298 to $328 \mathrm{~K}$, thus kinetic rate constant of the enzyme has no temperature dependency. No specific temperature term had to be added to the model; all trends for different solvent concentrations and temperatures are captured with a simple model and the normal variation of the solutions properties.

The MM and MR model could predict, the decrease of the liquid side mass transfer coefficient $\mathrm{k}_{\text {liq }}$ for higher $\mathrm{CO}_{2}$ partial pressures, whereas the SM and SP model could not. The differences between these models though seem to matter just for application with high $\mathrm{CO}_{2}$ partial pressure (eg. biogas upgrading), and not for CCS applications on coal burning power plants. In low $\mathrm{CO}_{2}$ partial pressure applications all 4 models seemed valid to describe the mass transfer at different $\mathrm{CO}_{2}$ gas partial pressures. 
Just the SP and MR model are capable of describing the trend of $\mathrm{k}_{\text {liq }}$ at different loadings. The MM and SM model tend to over predict the mass transfer substantially once the solvent is loaded.

For absorber just models that account for the influence of solvent loading on mass transfer should be implemented, like the SP or MR model, unless it is experimentally proven that this effect can be neglected.

All models over-predict the mass transfer for very high enzyme concentrations. The data indicate that the reaction rate and enzyme concentration relation is non-linear at high enzyme concentrations.

The MR model gave the best results overall, followed by the SP model which was slightly worse. Both models could predict the mass transfer flux from experiments in a wide range of process conditions within $13 \%$ accuracy for absorption and $25 \%$ for desorption. The MM and SM models performed substantially worse, which can be attributed to the missing influence of solvent loading on the mass transfer. The results show that solvent loading is one of the most important process conditions on the enzyme kinetics, more important than the substrate saturation by $\mathrm{CO}_{2}$.

The wide range of process conditions makes the SP and MR model suitable to be implemented into absorber and desorber column model. This will lead to a more accurate simulation of the carbon capture process with CA enhanced MDEA and can contribute to benchmark the enzyme enhanced solvent technology with conventional processes.

\section{Acknowledgement}

The authors would like to acknowledge funding from the INTERACT project (European Union Seventh Framework Programme FP7/2007-2013 under grant agreement $n^{\circ}$ 608535) and from the Technical University of Denmark. 
The author would also like to thank Kaj Thomsen for help and assistance with the extended UNIQUAC model and Jozsef Gaspar for help with the GM model for the enhancement factor. 


\section{References:}

[1] H. F. Svendsen, E. T. Hessen, and T. Mejdell, "Carbon dioxide capture by absorption, challenges and possibilities," Chem. Eng. J., vol. 171, no. 3, pp. 718-724, 2011.

[2] S. Salmon and A. House, Novel Materials for Carbon Dioxide Mitigation Technology, Chapter 2 - Enzyme-catalyzed Solvents for CO2 Separation. Elsevier B.V., 2015.

[3] P. Grunwald, Biocatalysis, 1st ed. Imperial College Press, 2011.

[4] N. U. Meldrum and F. J. W. Roughton, "Carbonic anhydrase and the state of carbon dioxide in the blood," Nature, vol. 131, p. 874-875 ST-Carbonic anhydrase and the state of, 1933.

[5] A. C. Pierre, "Enzymatic Carbon Dioxide Capture," ISRN Chem. Eng., vol. 2012, pp. 122, 2012.

[6] S. C. Frost and R. McKenna, Carbonic Anhydrase: Mechanism, Regulation, Links to Disease, and Industrial Applications, vol. 75. Springer, 2014.

[7] C. Tu, R. S. Rowlett, B. C. Tripp, J. G. Ferry, and D. N. Silverman, "Chemical rescue of proton transfer in catalysis by carbonic anhydrases in the $\beta$ - and $\gamma$-class," Biochemistry, vol. 41, no. 51, pp. 15429-15435, 2002.

[8] B. C. Tripp, K. Smith, and J. G. Ferry, "Carbonic Anhydrase: New Insights for an Ancient Enzyme,” J. Biol. Chem., vol. 276, no. 52, pp. 48615-48618, 2001.

[9] Y. Pocker and D. W. Bjorkquist, "Comparative studies of bovine carbonic anhydrase in $\mathrm{H} 2 \mathrm{O}$ and D2O. Stopped-flow studies of the kinetics of interconversion of $\mathrm{CO} 2$ and $\mathrm{HCO} 3$ -," Biochemistry, vol. 16, no. 26, pp. 5698-5707, 1977.

[10] N. J. M. C. Penders-van Elk, P. W. J. Derks, S. Fradette, and G. F. Versteeg, "Kinetics of absorption of carbon dioxide in aqueous MDEA solutions with carbonic anhydrase at 298K," Int. J. Greenh. Gas Control, vol. 9, pp. 385-392, 2012.

[11] H. Bisswanger, Practical Enzymology Enzymes in Industry Biocatalysts and Enzyme Technology, 2nd ed. Wiley-VCH, 2008.

[12] M. E. Russo, P. Bareschino, G. Olivieri, R. Chirone, P. Salatino, and A. Marzocchella, "Modeling of slurry staged bubble column for biomimetic CO2 capture," Int. J. Greenh. Gas Control, vol. 47, pp. 200-209, 2016.

[13] T. Praveen, P. Valencia, and L. Rajendran, "Theoretical analysis of intrinsic reaction kinetics and the behavior of immobilized enzymes system for steady-state conditions," Biochem. Eng. J., vol. 91, pp. 129-139, 2014.

[14] I. H. Segel, Enzyme Kinetics: Behavior and Analysis of Rapid Equilibrium and SteadyState Enzyme Systems. Wiley-VCH, 1993.

[15] A. Cornish-Bowden, Principles of ezyme kinetics. Butterworths Inc, 1976.

[16] F. Larachi, O. Lacroix, and B. P. a Grandjean, "CO 2 hydration by immobilized carbonic anhydrase in Robinson-Mahoney and packed-bed scrubbers-Role of mass transfer and inhibitor removal," Chem. Eng. Sci., vol. 73, pp. 99-115, 2012.

[17] N. J. M. C. Penders-van Elk, C. Van Aken, and G. F. Versteeg, "Influence of temperature 
on the kinetics of enzyme catalysed absorption of carbon dioxide in aqueous MDEA solutions," Int. J. Greenh. Gas Control, vol. 49, pp. 64-72, 2016.

[18] S. Zhang and Y. Lu, "Kinetic performance of CO2 absorption into a potassium carbonate solution promoted with the enzyme carbonic anhydrase: Comparison with a monoethanolamine solution," Chem. Eng. J., vol. 279, pp. 335-343, 2015.

[19] G. Hu, K. H. Smith, N. J. Nicholas, J. Yong, S. E. Kentish, and G. W. Stevens, "Enzymatic carbon dioxide capture using a thermally stable carbonic anhydrase as a promoter in potassium carbonate solvents," Chem. Eng. J., vol. 307, pp. 49-55, 2016.

[20] M. E. Russo, G. Olivieri, A. Marzocchella, P. Salatino, P. Caramuscio, and C. Cavaleiro, "Post-combustion carbon capture mediated by carbonic anhydrase," Sep. Purif. Technol., vol. 107, pp. 331-339, 2013.

[21] N. J. M. C. Penders-van Elk, C. van Aken, and G. F. Versteeg, "Influence of temperature on the kinetics of enzyme catalysed absorption of carbon dioxide in aqueous MDEA solutions," Int. J. Greenh. Gas Control, vol. 49, pp. 64-72, 2016.

[22] B. R. W. Pinsent, L. Pearson, and F. J. W. Roughton, "The Kinetics of Combination of Carbon Dioxide with Hydroxide Ions," Trans. Faraday Soc., vol. 53, no. 1512, p. 160, 1956.

[23] G. F. Versteeg, L. A. J. . van Dijck, and W. P. M. van Swaaij, "On the Kinetics between $\mathrm{CO} 2$ and Alkanolamines both in aqueous and non-aqueous solutions. An overview," Chem. Eng. Commun., vol. 144, pp. 113-158, 1996.

[24] P. D. Vaidya and E. Y. Kenig, "CO2-Alkanolamine Reaction Kinetics: A Review of Recent Studies," Chem. Eng. Technol., vol. 30, no. 11, pp. 1467-1474, 2007.

[25] W. P. M. van Swaaij and G. F. Versteeg, "Mass transfer accompanied with complex reversible chemical reactions in gas-liquid systems: an overview," Chem. Eng. Sci., vol. 47, no. 13-14, pp. 3181-3195, 1992.

[26] J. Gaspar and P. L. Fosbøl, "A general enhancement factor model for absorption and desorption systems: A CO2 capture case-study," Chem. Eng. Sci., vol. 138, pp. 203-215, 2015.

[27] J. Gaspar and P. L. Fosbøl, "Practical Enhancement Factor Model based on GM for Multiple Parallel Reactions: Piperazine (PZ) CO2 Capture," Chem. Eng. Sci.

[28] C. Huang and C. Kuo, "Mathematical Model for Mass Transfer Accompanied by Reversible Chemical Reaction," AIChE J., vol. 9, no. 2, pp. 161-167.

[29] C. S. Chang and G. T. Rochelle, "Mass transfer enhanced by equilibrium reactions," Ind. Eng. Chem. Fundam., vol. 21, no. 4, pp. 379-385, 1982.

[30] A. Gladis, M. T. Gundersen, P. L. Fosbøl, J. M. Woodley, and N. von Solms, "Influence of temperature and solvent concentration on the kinetics of the enzyme carbonic anhydrase in carbon capture technology," Chem. Eng. J., 2017.

[31] T. L. Sønderby, K. B. Carlsen, P. L. Fosbøl, L. G. Kiørboe, and N. von Solms, "A new pilot absorber for $\mathrm{CO} 2$ capture from flue gases: Measuring and modelling capture with MEA solution," Int. J. Greenh. Gas Control, vol. 12, pp. 181-192, 2013.

[32] J. J. Ko, T. C. Tsai, C. Y. Lin, H. M. Wang, and M. H. Li, "Diffusivity of nitrous oxide in 
aqueous alkanolamine solutions," J. Chem. Eng. Data, vol. 46, no. 1, pp. 160-165, 2001.

[33] N. Sadegh, E. H. Stenby, and K. Thomsen, "Thermodynamic modeling of CO2 absorption in aqueous N-Methyldiethanolamine using Extended UNIQUAC model," Fuel, vol. 144, pp. 295-306, 2015.

[34] T. G. Spiro, Zinc Enzymes, 1st ed. John Wiley \& Sons Ltd., 1983.

[35] P. Mirjafari, K. Asghari, and N. Mahinpey, "Investigating the application of enzyme carbonic anhydrase for CO 2 sequestration purposes," Ind. Eng. Chem. Res., vol. 46, no. 3, pp. 921-926, 2007.

[36] H. Thee, K. H. Smith, G. da Silva, S. E. Kentish, and G. W. Stevens, "Carbonic anhydrase promoted absorption of CO2 into potassium carbonate solutions," Greenh. Gases Sci. Technol., vol. 5, pp. 108-114, 2015.

[37] S. Salmon, A. House, K. Liu, R. Frimpong, K. Liu, C. Freeman, G. Whyatt, J. Slater, D. Fitzgerald, and D. Babcock, "Low-energy solvents for carbon dioxide capture enabled by combination of enzymes and vacuum regeneration. Technical report," 2015. 
- $\mathrm{CO}_{2}$ mass transfer models developed for CA enhanced MDEA solutions.

- Mass transfer model on basis of mechanistic enzyme model.

- Influence of temperature, solvent concentration, $\mathrm{CO}_{2}$ partial pressure and solvent loading on enzyme kinetics described.

- Model validation for 298-328 K, 15-50 wt\% MDEA, up to $50 \mathrm{kPa} \mathrm{CO}_{2}$ for absorption and desorption. 